\title{
Recent Advances in Solar Energy Full Spectrum Conversion and Utilization
}

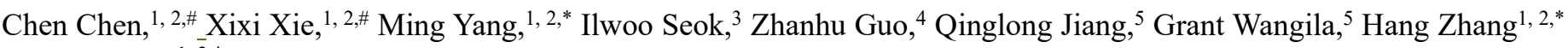
and Qibin $\mathrm{Liu}^{1,},{ }^{*}{ }^{*}$

\begin{abstract}
Photovoltaic technology is a direct and effective way to utilize solar energy. The mismatch between the absorption band of solar cells and the solar light band restricts solar energy's efficient use. Full-spectrum conversion of solar energy with spectral modification and coupling solar thermal application are reviewed. Additionally, implementing machine learning (ML) methods to improve solar energy utilization is also examined. With the utilization of up-conversion materials for solar cells, the solar-energy-utilization efficiency is enhanced. Combining PV and thermal applications have been validated to be promising for improving efficiency. With the development of computer science and the urgent need to design solar energy materials and forecast PV performances, ML methods in solar energy utilization have been successfully implemented into solar energy utilization.
\end{abstract}

Keywords: Solar-energy Utilization; Concentrating Photovoltaic; Up-conversion; Machine Learning.

Received: 9 December 2020; Accepted: 1 February 2021.

Article type: Review article.

\section{Introduction}

Solar energy is the most abundant alternative to fossil fuel, converted into electricity sustainably. ${ }^{[1,2]}$ In recent years, the solar energy utilization industry has experienced vigorous development and made rapid research or commercial achievements. Convert the sunlight into electric energy through semiconductor photovoltaic (PV) technology is a direct and effective way to utilize solar energy. According to the development history of solar cells (SCs), Green et al..$^{\left[{ }^{[3]}\right.}$ proposed that it could be divided into three stages: the first generation of bulk silicon solar cells including

1 Institute of Engineering Thermophysics, Chinese Academy of Sciences, Beijing 100049, China.

2 University of Chinese Academy of Sciences, No. 19(A) Yuquan Road, Beijing 100049, China.

3 Arkansas State University, PO Box 1740, State University, AR 72467, USA.

${ }^{4}$ Department of Chemical \& Biomolecular Engineering, University of Tennessee Knoxville, Knoxville, TN 37996, USA.

${ }^{5}$ Department of Chemistry and Physics, University of Arkansas, Pine Bluff, Arkansas 71601, USA.

*Email: yangming@iet.cn (Y. Ming), zhanghang@iet.cn (H. Zhang), qibinliu@iet.cn (Q. Liu)

\#Both authors contributed equally to this work. monocrystalline silicon and polycrystalline silicon, ${ }^{[4]}$ the second generation of thin-film solar cells including amorphous silicon, ${ }^{[5]}$ gallium arsenide (GaAs), ${ }^{[6]}$ cadmium telluride (CdTe) and copper indium gallium selenium (CIGS) thin-film cells, ${ }^{[7]}$ and the third generation new battery with improved structure and battery performance. The current commercial solar modules are mostly based on crystalline silicon (c-Si) singlejunction solar cells. In 2017, laboratory silicon heterojunction solar cells with record power conversion efficiency (PCE) over $26 \%{ }^{[8]}$ had been demonstrated to approach the theoretical PCE limit of Si solar cells, $29.1 \%{ }^{[9]}$ Meanwhile, perovskite solar cells (PSCs) have become a hot research area recently. Since the first use in 2009, the PCE of thin-film perovskite solar cells has increased from $3.8 \%{ }^{[10]}$ to $25.2 \%$, according to statistical data from NREL. ${ }^{[1]}$ The maximum efficiency of different kinds of laboratory SCs is shown in Fig. 1.

Despite the ongoing improvement of SCs, the PCE of single-junction solar cells is curtailed by the ShockleyQueisser (SQ) efficiency limit of $31 \%{ }^{[12]}$ The energy utilization of sunlight mainly comes from solar radiation, which has a vast continuous spectrum and tens of thousands of absorption and emission lines. The main difficulty in improving photovoltaic energy conversion efficiency lies in the spectral mismatch between the energy distribution of photons in the incident solar spectrum and the bandgap of semiconductor material. As well known, the spectral 


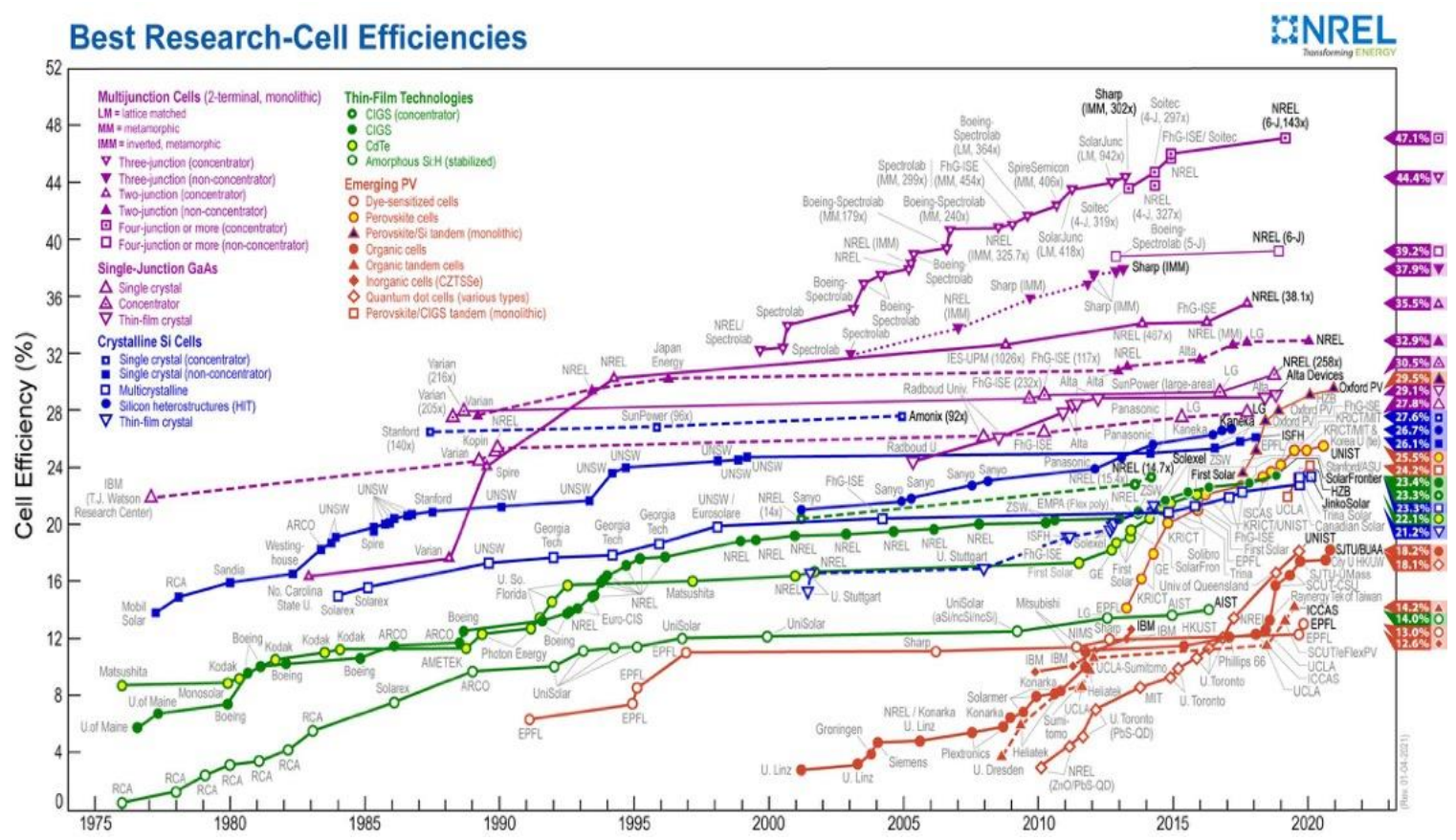

Fig. 1 Statistical chart of maximum efficiency of laboratory solar cell by NREL reproduced with the permission from [11], Copyright the National Renewable Energy Laboratory, Golden, CO.

distribution of sunlight consists of photons with broad wavelengths ranging from UV to IR $(280 \mathrm{~nm}-2500 \mathrm{~nm})$. In the total radiation energy, the infrared region with a wavelength greater than $780 \mathrm{~nm}$ accounts for about $52 \%$ of the total solar energy, followed by the visible region with a spectral wavelength between $390-780 \mathrm{~nm}$, accounting for about $45 \%$ of the total solar energy. ${ }^{[13]}$ However, the catalytic material is limited by the particular energy level structure and can only absorb the sunlight in a specific band. The photon below the bandgap does not have quantum interaction with the catalytic material, which means that a large proportion of infrared light energy will eventually be converted into heat.

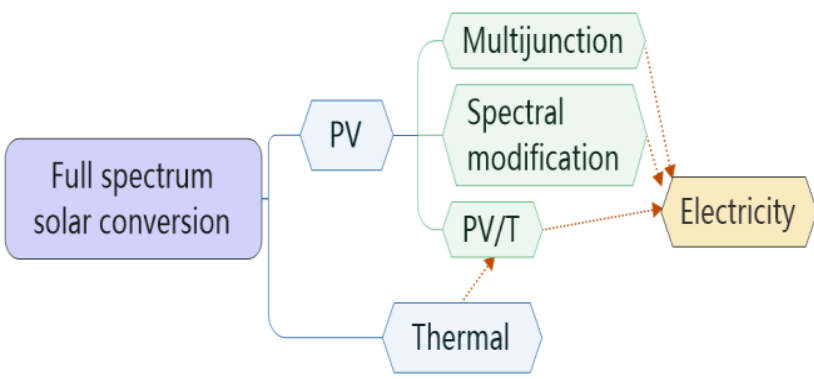

Fig. 2 Flexible paths of full-spectrum solar conversion.

As full-spectrum sunlight can harvest solar energy utilization, a lot of research has been conducted to minimize the incident photons' loss. Fig. 2 shows the three primary paths to achieve this purpose. As shown in Fig. 2, solar energy full spectrum conversion can be realized by stacking solar cells of appropriate bandgaps in multijunction configuration, modifying the incident spectrum, and coupling solar thermal application $(\mathrm{PV} / \mathrm{T})$ to utilize the heat converted from the infrared light. Multijunction configuration is technically simple by stacking solar cells with different materials. Spectral modification is to modify the incident photons to appropriate energy by spectral modification materials. ${ }^{[14]}$ Up-conversion (UC), down-conversion (DC), and luminescent down-shifting (LDS) materials ${ }^{[15]}$ are introduced to deal with the incident light making the infrared low-frequency and high-frequency ultraviolet light that cannot be effectively used in the light with proper frequency. As solar thermal technology utilizes a full spectrum of sunlight by converting photonic energy into heat, coupling solar thermal application with the PV is also promising. The PV/T system consists of a PV component and a thermal collector placed at the bottom of the PV component. The PV/T system's PV/T system can be enhanced due to a lower operating temperature since the solar electrical efficiencies for crystalline silicon cells and amorphous silicon cells decrease by $0.5 \%$ and $0.25 \%$, respectively, for $1{ }^{\circ} \mathrm{C}$ temperature increasing. ${ }^{[16]}$ The thermal collector absorbs the heat from the PV component and releases it for thermal applications, including domestic hot water. In this paper, fullspectrum conversion and solar energy utilization with spectral modification and coupling solar thermal application are reviewed extensively. Accompany with the converging technology of spectral modification and coupling solar thermal application, another cutting-edge technology, i.e., the machine learning (ML) method, has attracted worldwide attention in solar energy utilization to the development of computer science and data science. Sharing the same objective to utilize solar energy, they are also coupled for better performance. Besides the conventional perspectives of materials and systems in solar energy full spectrum utilization, this paper also provides the recent progress of utilizing the ML method in solar energy utilization. 
a)

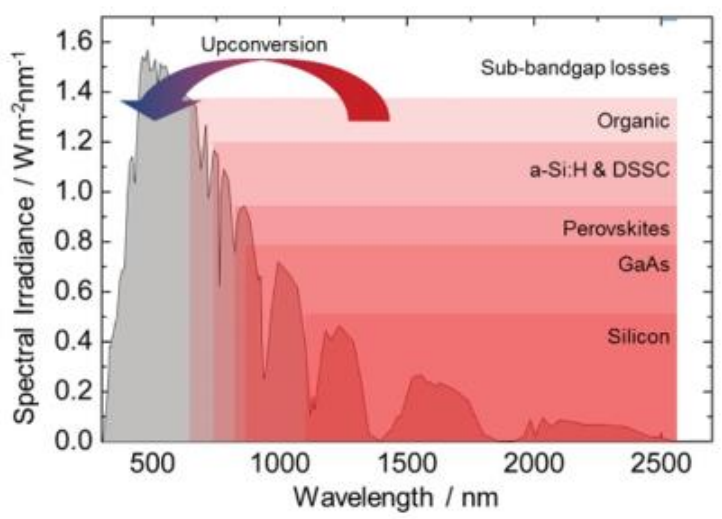

b)

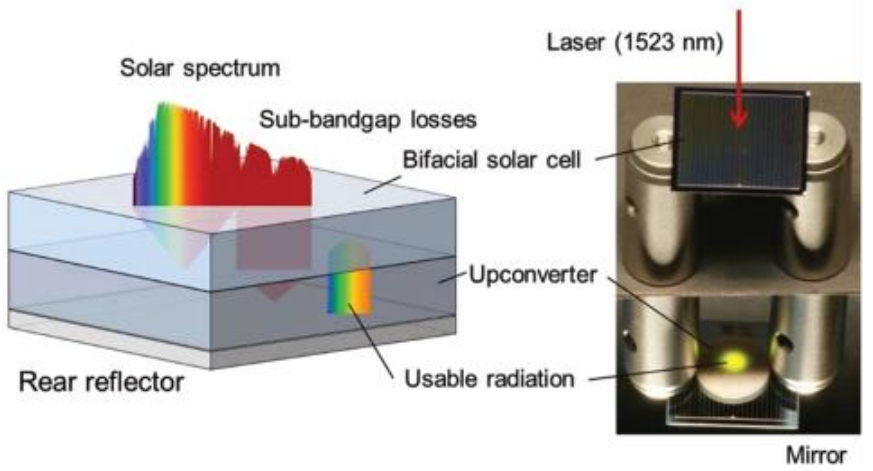

Fig. 3. (a) Single-junction solar cells suffer from considerable losses (indicated in red) because photons with energies below the solar cell's absorption threshold do not provide sufficient energy for the excitation of electron-hole pairs. By converting at least two low-energy photons into one usable high-energy photon, upconversion reduces these losses. (b) The photograph shows an upconverting solar cell device under laser illumination, reproduced with the permission from [18], Copyright 2015 WILEY-VCH Verlag GmbH \& Co.

\section{Spectral conversion materials}

There are three spectral modification processes, i.e., upconversion, down-conversion, and luminescent downshifting. Up-conversion material ${ }^{[17]}$ is a kind of optical conversion material that can convert low-energy photons into high-energy photons. In other words, it is a kind of fluorescence material with short wave excitation and long-wave emission. A singlephoton with energy less than the bandgap cannot be absorbed. But when the energies of two or more photons are combined into a single photon, this new photon with high energy could excite electrons into the conduction band and produce more currents. As shown in Fig. 3(a), the extent of these transmission or sub-bandgap losses depends on the considered solar-cell technology's absorption threshold. The upconversion would help to reduce these losses, especially for perovskite and organic solar cells. Fig. 3(b) gives a sample of an upconverting solar cell device under laser illumination. The upconverter is placed at the rear side of a bifacial solar cell. A rear reflector helps to capture the upconverter's emission. A mirror is placed underneath the device such that the upconverter and the visible up-conversion luminescence can be seen. ${ }^{[18]}$

On the other hand, solar cells give the best photovoltaic response at wavelengths closer to the bandgap. Therefore, spectral modification in the opposing direction would also work. Both down-conversion and luminescent down-shifting processes can produce lower energy photons from ones of higher energy. But until recently, there were few physical DCPV systems fabricated or experiments reported to demonstrate an efficiency lifting with DC materials. But studies for the utilization of DC materials in solar cells increased recently. Dumont et al. prepared $\mathrm{Tb}^{3+}-\mathrm{Yb}^{3+}$ co-doped Silicon- Nitride matrix DC layers, and its yield was improved from prior studies. It was deemed suitable for applying a silicon solar cell due to the efficient emission of $980 \mathrm{~nm}$ light following $325 \mathrm{~nm}$ illumination. ${ }^{[19]}$

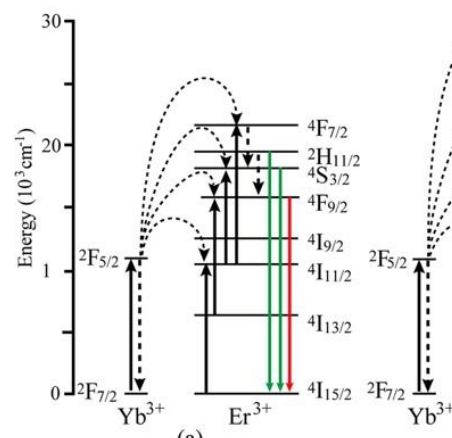

Fig. 4. UC mechanism of the lanthanide UC materials (a) $\mathrm{Yb}^{3+}$ and $\mathrm{Er}^{3+}$, (b) $\mathrm{Yb}^{3+}$ and $\mathrm{Tm}^{3+}$ and (c) $\mathrm{Yb}^{3+}$ and $\mathrm{Ho}^{3+}$, reproduced with permission from [23], Copyright 2014 American Chemical Society.

In this paper, we focus on up-conversion materials and their application for solar cells. Up-conversion was first proposed by Bloembergen ${ }^{[20]}$ in 1959 . He found that rare earth metal compounds could absorb IR radiation then reemit at a shorter wavelength, acting as quantum counters known as upconversion. To date, two main classes of materials have been studied for UC emission. These are the UC emission of lanthanide ions, $\mathrm{Ln}^{\mathrm{x}}$, $\left[\right.$ such as Erbium $\left(\mathrm{Er}^{3+}\right)$, Holium $\left(\mathrm{Ho}^{3+}\right)$, and Thulium $\left.\left(\mathrm{Tm}^{3+}\right)\right]$, in an inorganic host and the triplettriplet annihilation (TTA)- based UC. Upconverting nanocrystals are generally comprised of an inert host material doped with sensitizer and activator lanthanide ions. Usually, fluorides exhibit lower phonon energies and high chemical stability and are often used as host materials for UC processes. $\mathrm{NaYF}_{4}$ is the most popular host for lanthanide UC materials. ${ }^{[21}$, 22] $\mathrm{Yb}^{3+}$ has a larger absorption cross-section than those of the other dopant lanthanide activators, such as $\mathrm{Er}^{3+}, \mathrm{Tm}^{3+}$, and $\mathrm{Ho}^{3+}$. The $2 \mathrm{~F}_{7 / 2}-2 \mathrm{~F}_{5 / 2}$ transition of $\mathrm{Yb}^{3+}$, which can be excited by a 980-nm laser, is conveniently resonant with many $\mathrm{f}-\mathrm{f}$ transitions of $\mathrm{Er}^{3+}, \mathrm{Tm}^{3+}$, and $\mathrm{Ho}^{3+}$, facilitating efficient ET from $\mathrm{Yb}^{3+}$ to these ions, as shown in Fig. 4. ${ }^{[23]}$ The most 
(a)

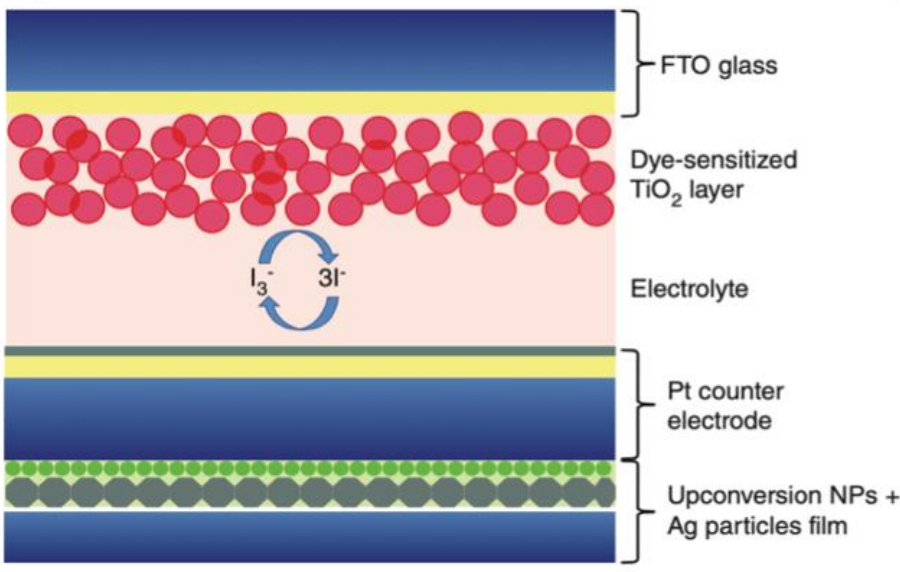

(b)

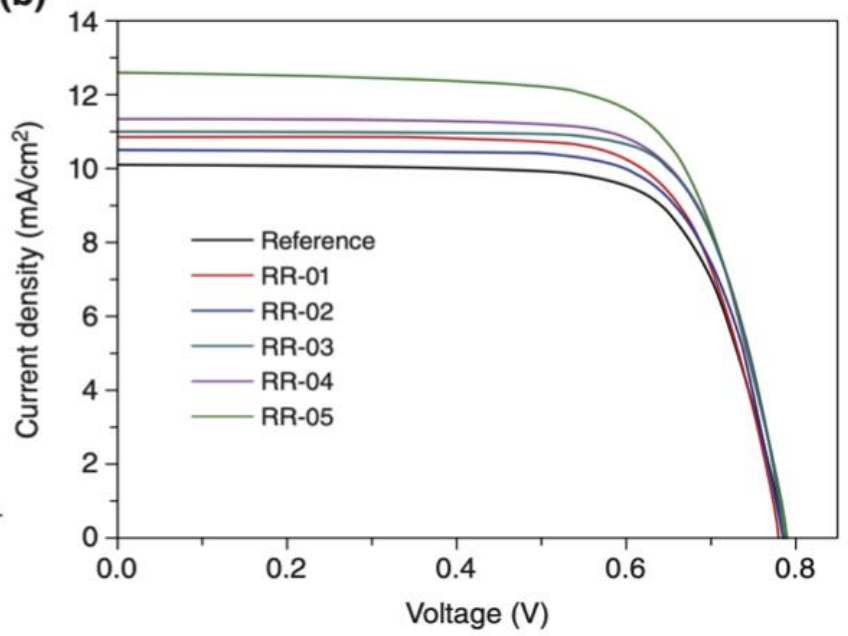

Fig. 5 (a) Schematic diagram of DSSCs with UC and plasmonic rear reflector film. (b) J-V curves of DSSCs with different films, reproduced with the permission from [31], Copyright 2014 Royal Society Of Chemistry.

efficient up-conversion has been reported for the lanthanide ion couples $(\mathrm{Yb}, \mathrm{Er})$ and $(\mathrm{Yb}, \mathrm{Tm}) \cdot{ }^{[24]} \mathrm{Like} \mathrm{UC}$ via rare-earth ions, the TTA process can be evidenced by the fluorescent intensity's quadratic dependence on incident light power since TTA involves an interaction between two sensitized triplet acceptor molecules. ${ }^{[25]}$

So far, up-conversion materials ${ }^{[26]}$ have been synthesized and used to minimize the solar-cell-based energy conversion process losses. For further utilization of solar energy, the upconversion effect has been considered as a promising route for spectral widening in photovoltaic devices, such as dyesensitized solar cells (DSSCs), ${ }^{[27]}$ organic solar cells, siliconbased solar cells, and perovskite solar cells. ${ }^{[28]}$ Since its discovery, up-conversion materials have been widely used in lasers, biomedicine, and display. Compared with the traditional fluorescent materials, there is an anti-Stokes phenomenon in this material. The earliest up-conversion materials were realized on phosphors. Then, the up-conversion luminescence phenomenon also appeared in selenides, with the conversion efficiency greatly improved. At present, there are three types of up-conversion luminescence, i.e., excitedstate absorption, energy transfer, and photon avalanche. ${ }^{[29]}$ Although researchers have gradually noticed the idea of upconversion materials used in efficient solar energy conversion, it is mainly used in solar cells. A. Shalav et al. attached the upconversion luminescent material $\mathrm{NaYF}_{4}: \mathrm{Er}^{3+}$ on the back of the solar cell to improve the photoelectric conversion efficiency by enhancing the near-infrared partial responsivity of the solar cell. ${ }^{[30]}$ In the application process, it is found that the external quantum efficiency of the battery is the highest when using $2.5 \%$ up-conversion phosphor. Ramasamy and Kim reported Ag particles' use with an upconverting layer for dye-sensitized solar cells (DSSCs). ${ }^{[31]}$ The authors then investigated the effect of five different layers on the solar cell performance. The schematic diagram of the constructed DSSC

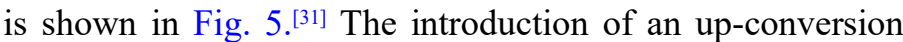

layer can adjust the solar spectrum and improve the photoelectric performance of DSSCs from the effective matching between the response curve and the spectrum.

Up-conversion in solar cells was calculated to lead to a maximum conversion efficiency of $47.6 \%$ potentially. Applied on the back of silicon solar cells, the efficiency limit would be approximately $37 \%{ }^{[26]}$ The analysis of the incident AM1.5G spectrum's energy content shows that silicon SCs with an upconverter layer would benefit from an extra amount of $35 \%$ incident light. ${ }^{[32]}$ The application of rare-earth-doped upconversion in double-sided silicon solar cells was described by Pan. ${ }^{[33]}$ They believe that the two-sided structure can absorb the light emitted from the conversion luminescence layer to verify that they take two practical methods to test the battery piece: one is directly coated with up-conversion phosphor solar cell, the other uses powder dissolved in silicone gel. The results of both methods show that these phosphors can be effectively used by solar cells. Bernd Ahrens et al. used the heat treatment method to compound neodymium and chloride ions to enhance fluoroacetate glass luminescence. They found that Er glass's doping makes the phosphor more suitable to be used as the up-conversion luminescence layer of silicon solar cells in theory. ${ }^{[34]} \mathrm{J}$. De Wild et al. applied $\mathrm{NaYF}_{4}: \mathrm{Yb}^{3+}, \mathrm{Er}^{3+}$ near-infrared conversion luminescent materials on the back of porous silicon solar cells. Because the materials absorb the reflected light and convert them into near-infrared light, the infrared radiation effect is enhanced. ${ }^{[35,36]}$ The results show that the current per unit area increases by $10 \mu \mathrm{M} / \mathrm{cm}^{2}$ under laser irradiation.

The UC luminescent nanomaterials have emission spectra in the range of $400-700 \mathrm{~nm}$, which coincides with the absorption of perovskite solar cells (PSCs). The application of UC materials in PSCs is beneficial for efficiency lifting. There have been different approaches in choosing where to put the UC materials. Fischer et al ${ }^{[37]}$ applied a visibly transparent $\mathrm{LiYF}_{4}: \mathrm{Yb}^{3+}, \mathrm{Er}^{3+}$ single crystal on top of the PSC to increase 
Table 1 Lanthanide-doped up-conversion materials used for PV applications.

\begin{tabular}{|c|c|c|c|c|c|}
\hline $\begin{array}{l}\text { Dopant } \\
\text { ion }\end{array}$ & Host & Excitation(nm) & Emission(nm) & Solar cell & Ref \\
\hline $\mathrm{Er}^{3+}$ & $\mathrm{NaYF}_{4}$ & 1523 & $550,660,800,980$ & $\mathrm{c}-\mathrm{Si}$ & [30] \\
\hline $\mathrm{Er}^{3+}$ & $\begin{array}{l}\text { Fluoride } \\
\text { glasses }\end{array}$ & 1532 & $550,660,820,980$ & c-Si & [40] \\
\hline $\mathrm{Ho}^{3+}$ & $\begin{array}{l}\text { Glass-ceramics } \\
\text { containing } \mathrm{PbF}_{2} \\
\text { nanocrystals }\end{array}$ & 1170 & 650,910 & c-Si & [41] \\
\hline $\begin{array}{l}\mathrm{Er}^{3+}- \\
\mathrm{Yb}^{3+}\end{array}$ & $\mathrm{Y}_{6} \mathrm{~W}_{2} \mathrm{O}_{15}$ & 973 & $516-570$ & GaAs & [44] \\
\hline $\begin{array}{l}\mathrm{Er}^{3+}- \\
\mathrm{Yb}^{3+}\end{array}$ & $\mathrm{NaYF}_{4}$ & 980 & $524,540,660$ & $\mathrm{a}-\mathrm{Si}$ & [43] \\
\hline $\begin{array}{l}\mathrm{Er}^{3+}- \\
\mathrm{Yb}^{3+}\end{array}$ & $\mathrm{LaF}_{3}$ & 980 & 543,655 & $\begin{array}{c}\text { Dye- } \\
\text { sensitized }\end{array}$ & [45] \\
\hline $\begin{array}{l}\mathrm{Tm}^{3+}- \\
\mathrm{Yb}^{3+}\end{array}$ & $\mathrm{Lu}_{2} \mathrm{O}_{3}$ & 980 & 476,653 & $\begin{array}{c}\text { Dye- } \\
\text { sensitized }\end{array}$ & [42] \\
\hline $\begin{array}{l}\mathrm{Er}^{3+}- \\
\mathrm{Yb}^{3+}\end{array}$ & $\mathrm{YF}_{3}$ & 975 & $510-560$ & Organic & [46] \\
\hline
\end{tabular}

the PCE by $7.9 \%$ under $7-8$ sun illumination. It is a straightforward method to apply UC materials to PSCs and broaden the absorption. Also, using UC materials in the electron transport layer (ETL) is a popular pathway. He et al. reported the utilization of $\mathrm{NaYF}_{4}: \mathrm{Yb} / \mathrm{Er}$ up-conversion nanoparticles (UCNPs) to replace the mesoporous layer of $\mathrm{TiO}_{2}$ in PSCs firstly. ${ }^{[28]}$ The power conversion efficiency (PCE) was increased to $17.8 \%$. The major challenge of using UC material in solar cells is that the defect and ligands on the surface of UC material would trap many photo-generated electrons and decrease the photocurrent in solar cells. To overcome the difficulty, Wang et al. reported the utilization of $\mathrm{Er}$ and $\mathrm{Yb}$ doped $\mathrm{TiO}_{2}\left(\mathrm{Er}-\mathrm{Yb}: \mathrm{TiO}_{2}\right)$ nanorod arrays as ETL of the PSCs and the PCE was enhanced to $20.8 \%{ }^{[38]}$ The introduction of UC nanomaterial into the commonly applied active layer of PSC was the most efficient way for improving the photoelectric performance of PSCs. A hydrophilic IR806 dye-sensitized UC nanocrystal IR806- $\beta$-NaYF4: $\mathrm{Yb}, \mathrm{Er}$ (IR806-UCNCs) was fabricated in 2017. ${ }^{[39]}$ By incorporating IR806-UCNCs into planar PSC, a PCE of $17.49 \%$ was received, made an increment of $29 \%$ compared with IR806UCNCs free devices. Table 1 gives more examples of upconversion materials used for PV applications. ${ }^{[30,40-46]}$

The results show that the up-conversion materials can optimize the solar energy spectrum. Up to now, up-conversion materials in solar hydrogen production lack systematic theoretical research and experimental level practical application, especially from the micro point of view, to explore the impact of various physical factors on the performance of such systems and their synergistic effects. How to select and control the up-conversion materials with the highest efficiency is worth investigating deeply.

\section{PV/T}

$\mathrm{PV} / \mathrm{T}$ technology has been investigated with various types of PV cells, including monocrystalline silicon (c-Si), polycrystalline silicon ( $\mathrm{p}-\mathrm{Si})$, ribbon silicon $(\mathrm{r}-\mathrm{Si})$, amorphous silicon (a-Si), cadmium telluride (CdTe), and copper indium gallium selenide (CIGS). ${ }^{[4]} \mathrm{PV} / \mathrm{T}$ systems can be divided into different categories based on heat extraction method or structure.
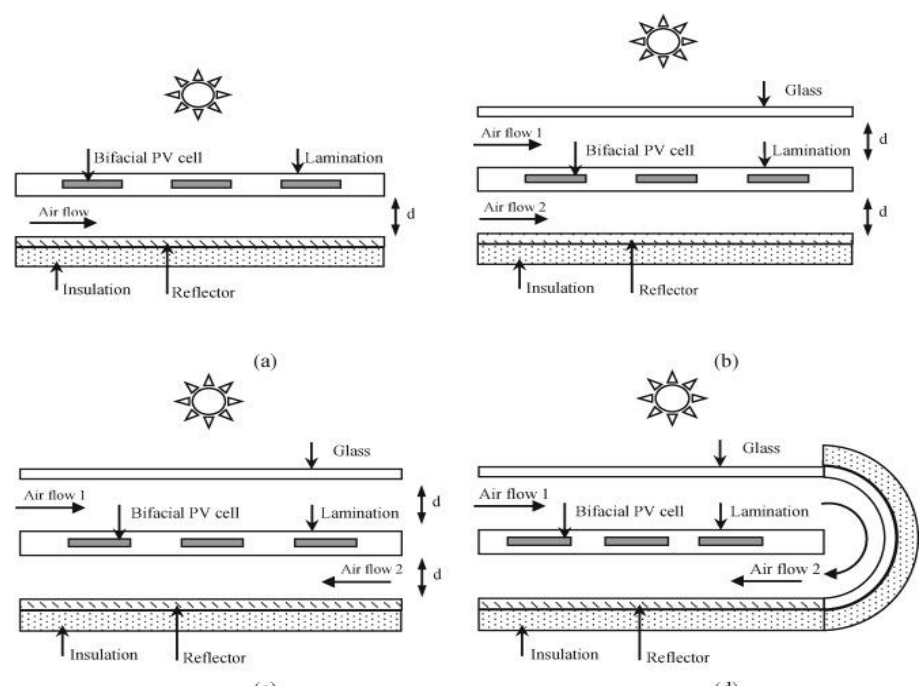

(c)

Fig. 6 Cross-sectional views of: (a) Model 1: single-path, bifacial PVT collector (b) Model 2: double-path, parallel flow, bifacial PVT collector (c) Model 3: double-path, counter flow, bifacial PVT collector (d) Model4: double-pass, returning flow, bifacial PVT collector, reproduced with the permission from [49], Copyright 2016 Elsevier. 


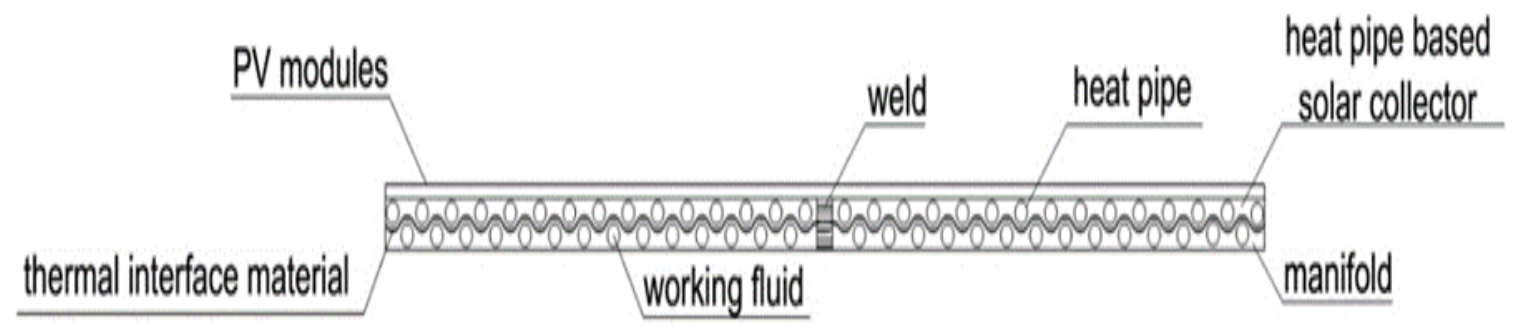

Fig. 7 The cross section of the flat heat pipe based solar hybrid PV/T solar panels, reproduced with the permission form [58], Copyright 2016 Elsevier.

Based on the heat extraction method, PV/T systems can be categorized into air-based, liquid-based, heat pipe-based, phase change material (PCM)-based, and thermoelectricbased systems. Air-based PV/T systems have a wide application, especially in space heating, ventilation, and drying of agricultural products due to their minimal use of materials and low operating costs. ${ }^{[47,48]}$ Ooshaksaraei et al. ${ }^{[49]}$ investigated four air-based bifacial photovoltaic thermal collectors in Fig. 6. The single-path collector design is the best option if electrical energy is the dominant desired output energy. However, a double-path parallel flow design is the best option if the thermal energy is the dominant desired output energy. The single-path design had the highest exergy efficiency $(8.2 \%-8.4 \%)$, followed by the double-path parallel flow design (7.2\%-8\%). Liquid-based PV/T systems have a better performance compared to air-based PV/T systems due to a higher thermal capacity. While water is the most accessible and the cheapest liquid coolant, nanofluids have been extensively proposed as more efficient coolants and optical filters for PV/T systems. So far, various nanoparticles, including carbon, ${ }^{[50]} \mathrm{SiC},{ }^{[51]}$ silver ${ }^{[52]}$ and gold ${ }^{[53]}$ have been used for the nanofluid-based PV/T. Based on the analysis performed by Hassani et al., ${ }^{[54]}$ nanofluid-based PV/T configuration with optimized optical and thermal properties produces more than twice of high-grade exergy annually than the water-based PV/T. Zhang et al. ${ }^{[5]}$ proposed a method to select proper nanofluids to decouple the solar irradiance for electricity and heat. Their results through the technique indicate that nanoparticle radius, ranging from $20 \mathrm{~nm}$ to $60 \mathrm{~nm}$, drove peak absorption movement from $395 \mathrm{~nm}$ to $520 \mathrm{~nm}$. Si cells' electrical efficiency and merit function value were $11.85 \%$ and 1.61 for $20 \mathrm{~nm}$ nanofluid, $11.0 \%$ and 1.66 for $20 / 40 \mathrm{~nm}$ (8:2) nanofluid. In comparison, those of GaAs cell were $9.30 \%$ and 1.92 for $20 \mathrm{~nm}$ nanofluid, $9.03 \%$, and 2.05 for $20 / 40 \mathrm{~nm}$ (8:2) nanofluid, respectively. As the heat pipe has very high thermal conduction, maintaining almost constant temperature has excellent application potential to be integrated with the $\mathrm{PV} / \mathrm{T}$ system. ${ }^{[56,57]}$ Taking the advantage of the efficient heat transfer process achieved by the heat pipe, Jouhara et al. ${ }^{[58,59]}$ developed a flat heat pipe based solar hybrid (PV/T) collector. Fig. 7 shows the cross section of the flat heat pipe based solar hybrid PV/T solar panels. The flat heat pipes were made from aluminum as the shell material and ammonia as the working fluid. They found the conversion efficiency of solar to thermal energy for the solar flat heat pipe collector was between 45.4 and $64.2 \%$. Additionally, Chen et al. ${ }^{[60]}$ proposed a heat-pipe solar (HPS) photovoltaic/thermal (PV/T) heat pump system (shown in Fig. 8), combining the HPS PV/T collector with a heat pump. A heat pump uses the extracted heat from the HPS PV/T collector. They found that the increase of PV backboard absorptivity leads to improving thermal application performance. The increases of supply water temperature in the condenser, PV packing factor, and heat pipe pitch impact the thermal application performance.

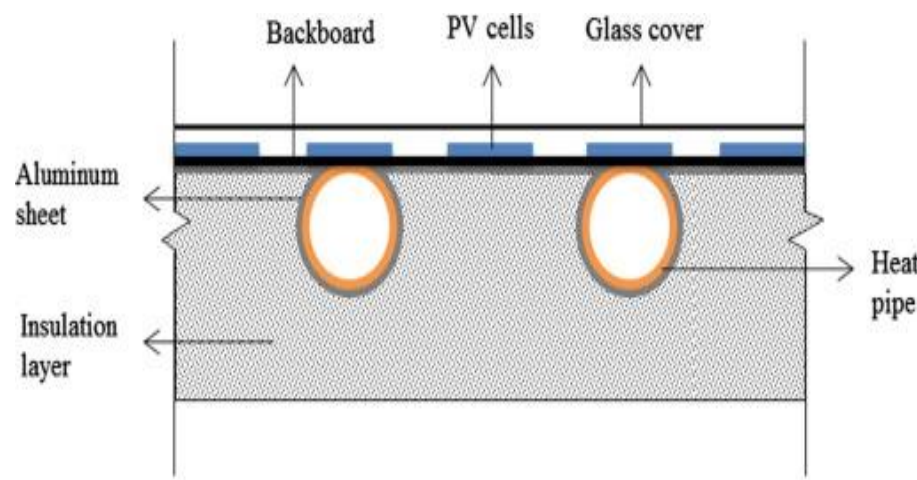

Fig. 8 Cross-section view of the HPS PV/T collector, reproduced with the permission from [60], Copyright 2017 Elsevier.

Phase change material (PCM), which can efficiently decrease a PV module's temperature by phase change, has also been used in PV/T. ${ }^{[61-63]}$ Preet et al. ${ }^{[64]}$ investigated the enhancement of using paraffin wax RT-30 in the PV/T system. Compared with water-based PV/T, PCM based PV/T has a lower operating temperature but a higher voltage. Yang et al. ${ }^{[61}$ proposed that integrating a PCM layer into a PV/T panel \%(shown in Fig. 9) reduced its heat loss to ambient effectively. The heat stored into the PCM can be discharged into the working fluid when the solar radiation is less intensive or unavailable, which improves the system's energy performance. Hossain et al..$^{[65]}$ developed a photovoltaic/thermal-phase change materials (PV/T-PCM) system and evaluated its energy, exergy, and economic performance. Lauric acid as PCM in leak-proof aluminum foil packets is placed around the flow channel, allowing an extended thermal storage period. They have achieved an exergy efficiency of $12.19 \%$ for the PV/TPCM system. As the thermoelectric (TE) module can provide an electrical output with a temperature difference, it can be attached to the PV cell backside as a tandem hybrid system to absorb electricity generation heat. ${ }^{[66,67]}$ However, the TE utilization is at the expense of reducing the system 


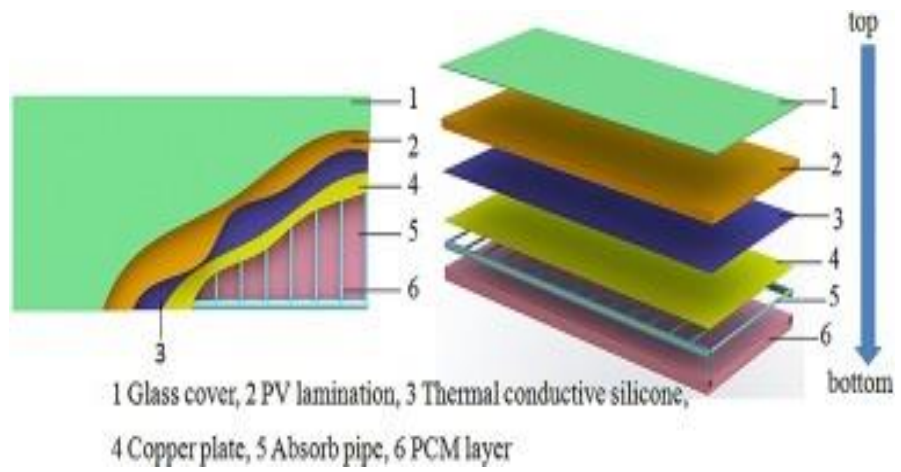

Fig. 9 Configuration of the PV/T-PCM module, reproduced with the permission from [61], Copyright 2017 Elsevier.

security and stability since the photovoltaic cell in the tandem hybrid system works at a higher temperature. ${ }^{[68]}$ Also, the PVTE generally requires concentrators to achieve such a high temperature, which is unnecessary for other heat extraction methods. ${ }^{[69,}$ 70] Tiwari et al. ${ }^{[71]}$ analyzed photovoltaic, thermoelectric flat plate collectors, which integrates the TE and water-based heat sink at the bottom of the PV panel (see Fig. 10). As shown in Fig. 10, the TE and water-based heat extraction methods are in series, i.e., the integrated TE modules produce electricity.

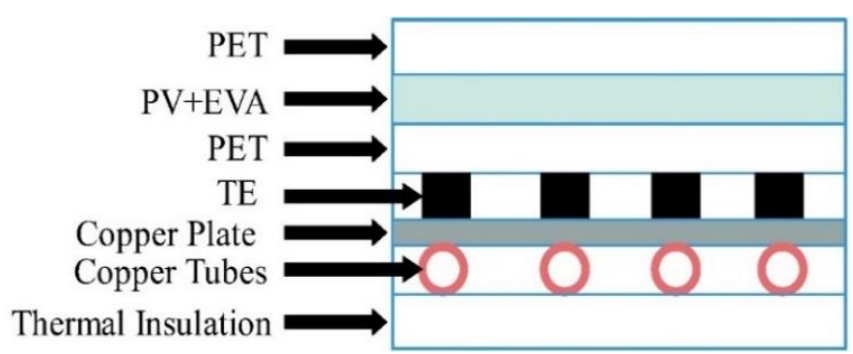

Fig. 10 Cross-sectional view of photovoltaic, thermoelectric flat plate collector, reproduced with the permission from [71], Copyright 2019 Elsevier.

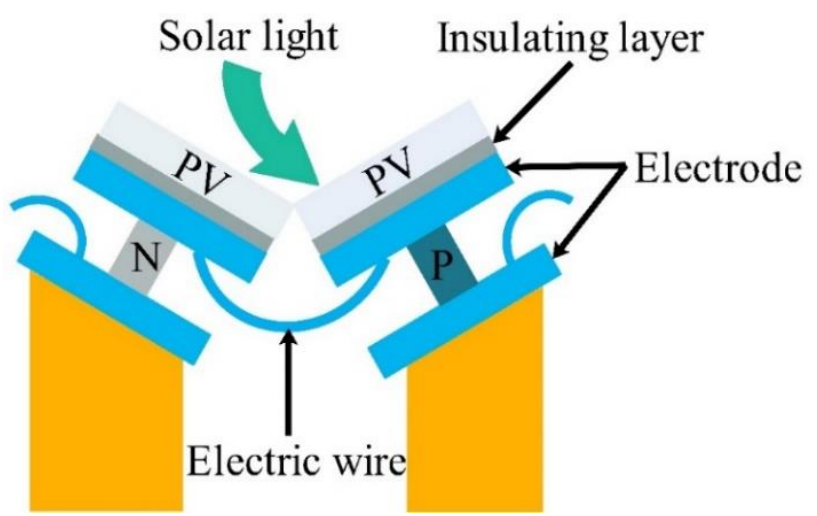

Fig. 11 PV-TE system with the V-type groove, reproduced with the permission from [73], Copyright 2018 Elsevier.

Simultaneously, the water, through tube-in-sheet collector configuration, extracts heat from the bottom surface of TE modules. Li et al. ${ }^{[72]}$ studied the geometry of the thermoelectric device in a PV-TE device. They pointed out that the optimum thermoelectric geometry in a hybrid PV-TE device dependedon the PV cell type. Zhang et al. ${ }^{[73]}$ designed a V-type groove shown in Fig. 11, to improve the heat transfer process leading to higher efficiency. Zhang et al. ${ }^{[74]}$ used the thermal lubricant between the PV cell and the TE device, which significantly improves the performance due to the enhanced heat transfer.

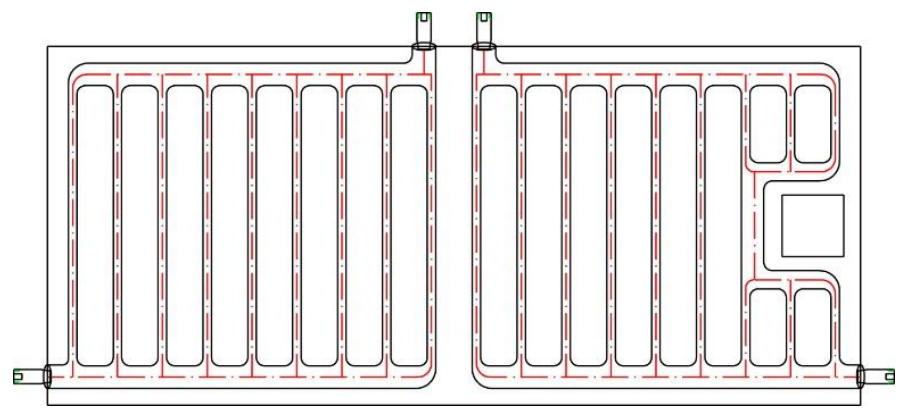

(a)

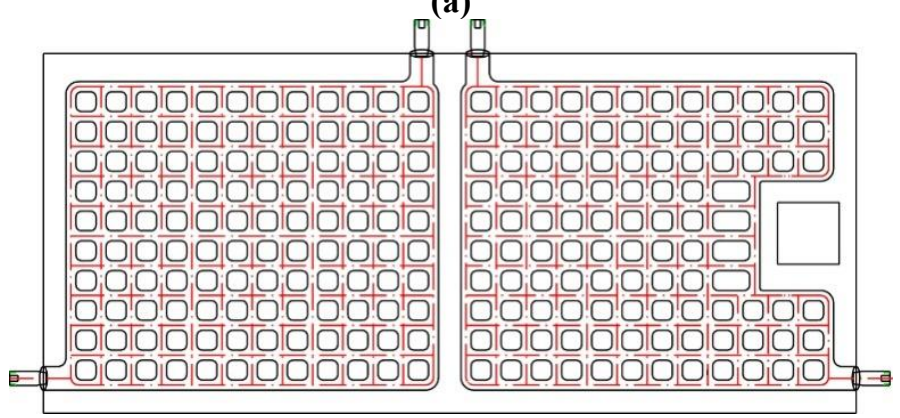

(b)

Fig. 12 Harp-channel (a) and grid-channel (b) absorber plate, reproduced with the permission from [64], Copyright 2019 Elsevier.

$\mathrm{PV} / \mathrm{T}$ systems can be classified into a flat plate for the structural aspect, building integrated systems, and concentrating systems. For the flat plate collectors, Yu et al. ${ }^{[64]}$ investigated the performance of a harp-channel configuration in Fig. 12(a) and a grid-channel arrangement in Fig. 12 (b). In their system, the working fluid of water is heated for domestic hot water supply. They found that the grid-channel PV/T collector had higher thermal and PV power efficiencies than those of the harp-channel collector, while the harp-channel $\mathrm{PV} / \mathrm{T}$ collector had much lower water flow pressure drop. Building integrated photovoltaic (BIPV) systems can be ideal for densely built environments, where traditional groundmounted systems cannot be easily used. ${ }^{[75]}$ Moreover, the $\mathrm{BIPV} / \mathrm{T}$ system becomes cheaper than ground-mounted systems due to the sharing of resources like materials and functions in the integration. ${ }^{[76]}$ Farshchimonfared et al., ${ }^{[77]}$ investigated the effect of the depth on a PV/T air collector linked to the mechanical air distribution system of a typical residential building. Fig. 13 shows the schematics of the PV/T air collector and integration of the $\mathrm{PV} / \mathrm{T}$ collector into the air distribution system of the building. Their results show that a smaller depth offers good performance at a higher air temperature rise, while a larger depth can deliver a better 


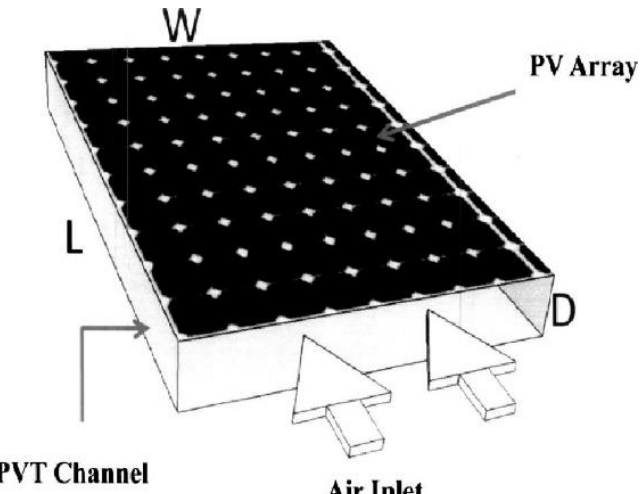

(a)

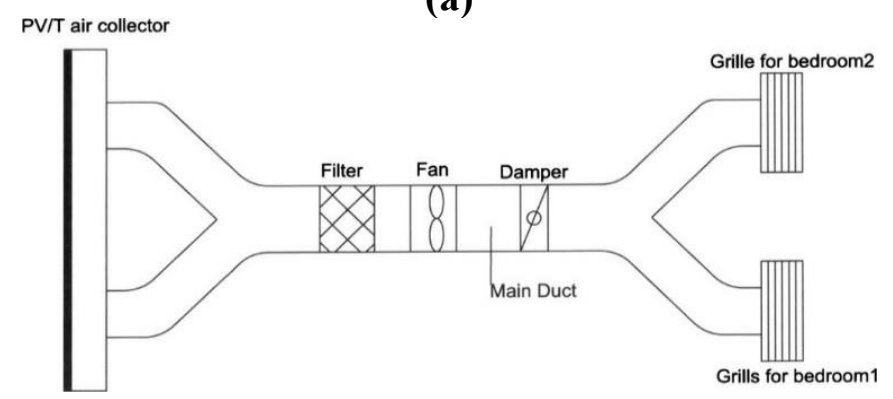

(b)

Fig. $13 \mathrm{~A} \mathrm{PV/T}$ air collector (a) and integration of the PV/T collector to the air distribution system (b) of the building, reproduced with the permission from the [77], Copyright 2016 Elsevier.

overall energy output but a lower temperature rise. Khanmohammadi et al. ${ }^{[47]}$ investigated an integrated system of a photovoltaic/thermal $(\mathrm{PV} / \mathrm{T})$ system with a thermal wheel
(TW) system for residential applications, which is capable of pre-heating/pre-cooling the ambient fresh air in winter/summer as well as producing electricity. They proposed that the coupled BIPV/T-TW system has a better thermal performance compared with the separated BIPV/T and TW systems, i.e., the annual energy efficiency and TW effectiveness of the optimized BIPV/T-TW system is $118.3 \%$ and $59.7 \%$ higher than that of the un-optimized system, while it has a slightly lower electrical performance compared with the BIPV/T system. Guo et al. ${ }^{[78]}$ developed a desiccant air dehumidification and cooling cycle that coupled ground source heat exchange and flat plate photovoltaic thermal $(\mathrm{PV} / \mathrm{T})$ collectors to provide conditioned air. The system cannot only maintain an office space within the thermal comfort zone for up to $93 \%$ of the time but save electrical energy up to $87 \%$ in comparison to a conventional dew point air dehumidification and cooling process.

Compared with conventional flat-plate $\mathrm{PV} / \mathrm{T}$ system, concentrating $\mathrm{PV} / \mathrm{T}$ system not only achieves larger solar irradiation for a fixed area but also generates hot working fluid at a higher temperature. ${ }^{[79,80]}$ In contrast, the major defect of the concentrating PV (CPV) technologies depends on the higher operating temperature caused by the concentrated solar energy, which weakens the power generation efficiency, ${ }^{[81,82]}$ There have been many types of research conducted relevant to the concentrator. While the solar irradiance on the flat-plate collector is relatively uniform, the concentrating PV's flux distribution appears to be non-uniform. Li et al. ${ }^{[83]}$ proposed a novel asymmetric compound parabolic concentrator concentrating PV with uniform flux distribution.

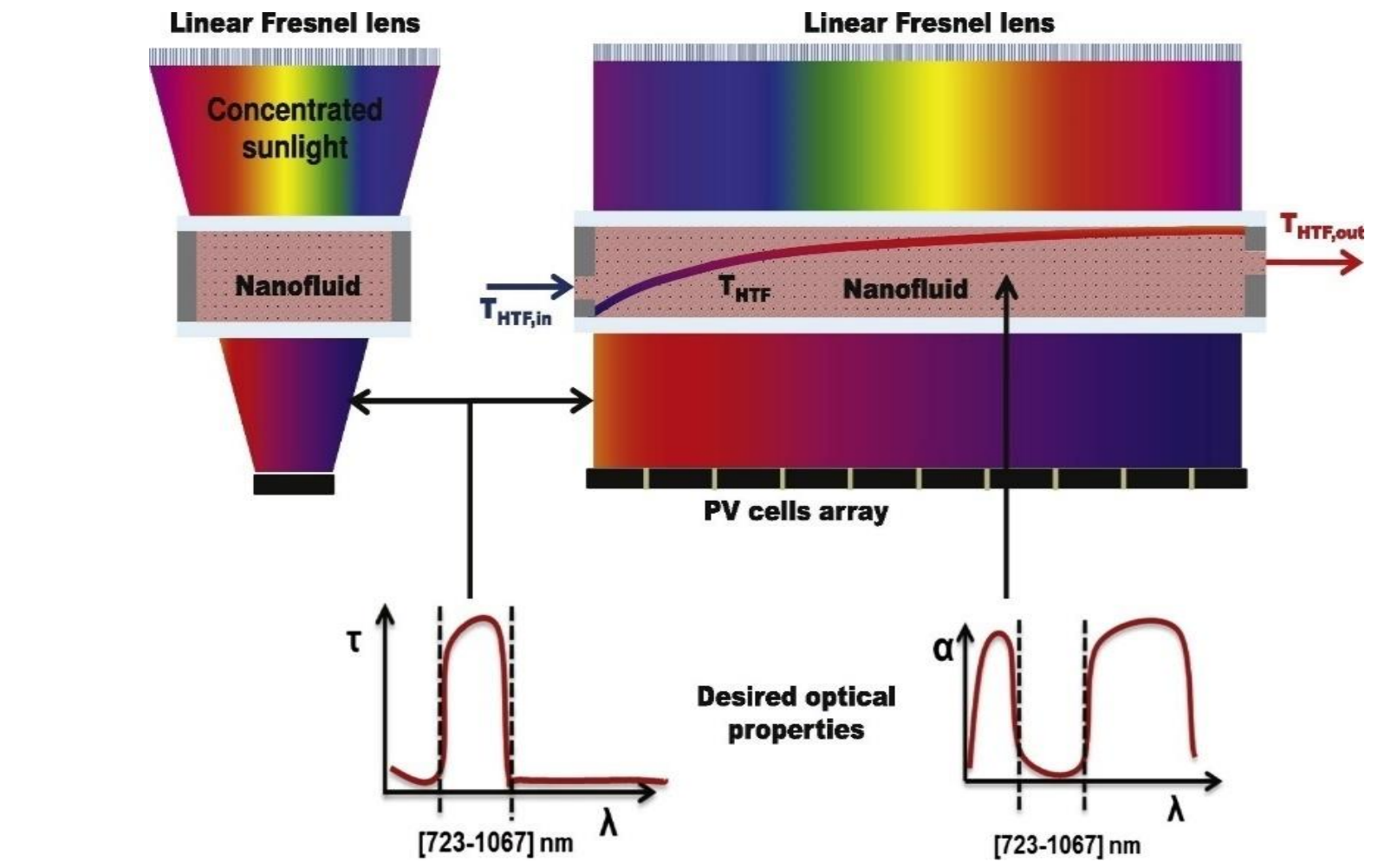

Linear Fresnel lens

Fig. 14 Conceptual design of the hybrid PV/T receiver, reproduced with the Permission form [86], Copyright 2017 Elsevier. 

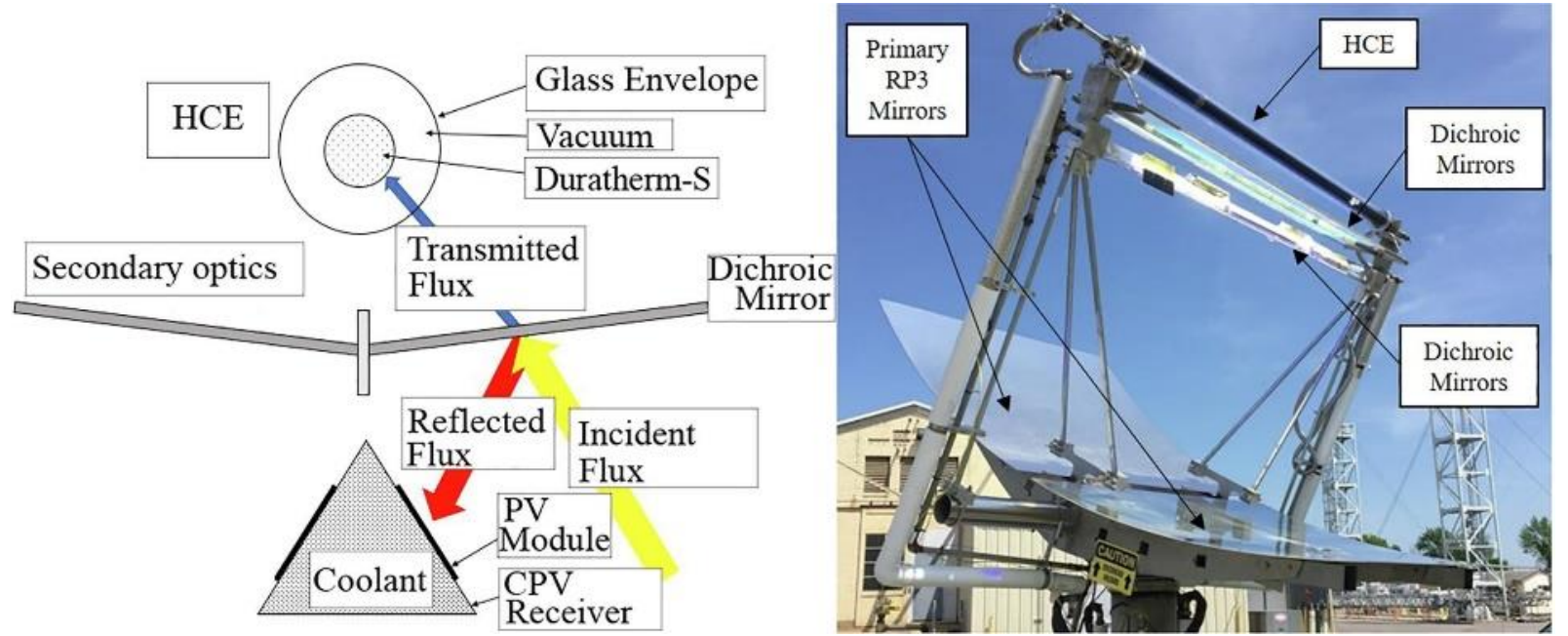

Fig. 15 Spectral beam splitting retrofit for existing CSP parabolic troughs to add concentrating photovoltaic power to output, reproduced with the permission from [87], Copyright 2020 International Solar Energy Society.

Furthermore, Bahaidarah et al.$^{[84]}$ investigated the effect of glazing on the concentrator. An unglazed PV-CPC system is recommended for greater electric power output, and a glazed system is recommended for higher thermal gain. As the efficiency can be improved by $\sim 5 \%$ for unconcentrated sunlight with the spectrum splitting system, ${ }^{[85]}$ i.e., wavelength below the bandgap-wavelength is directed to the PV component and the rest is directed to the thermal collector, the spectrum splitting $\mathrm{PV} / \mathrm{T}$ system with concentrator is also anticipated with higher efficiency. By controlling the material, size, and shape of nanoparticles, it is possible to achieve spectrally selective optical properties. Crisostomo et al. ${ }^{[86]}$ used $\mathrm{Ag}-\mathrm{SiO}_{2}$ nanoparticles in water to filter out the ideal spectrum for creating electricity from Si PV cells. Fig. 14 shows the design of the hybrid PV/T receiver. They pointed out that $12 \%$ more energy output can be achieved from this $\mathrm{PV} / \mathrm{T}$ prototype compared with a stand-alone $\mathrm{PV}$ system under the same illumination. Wingert et al. ${ }^{[87]}$ designed a spectral beam splitting retrofit (shown in Fig. 15) for existing concentrating solar power (CSP) parabolic troughs to add

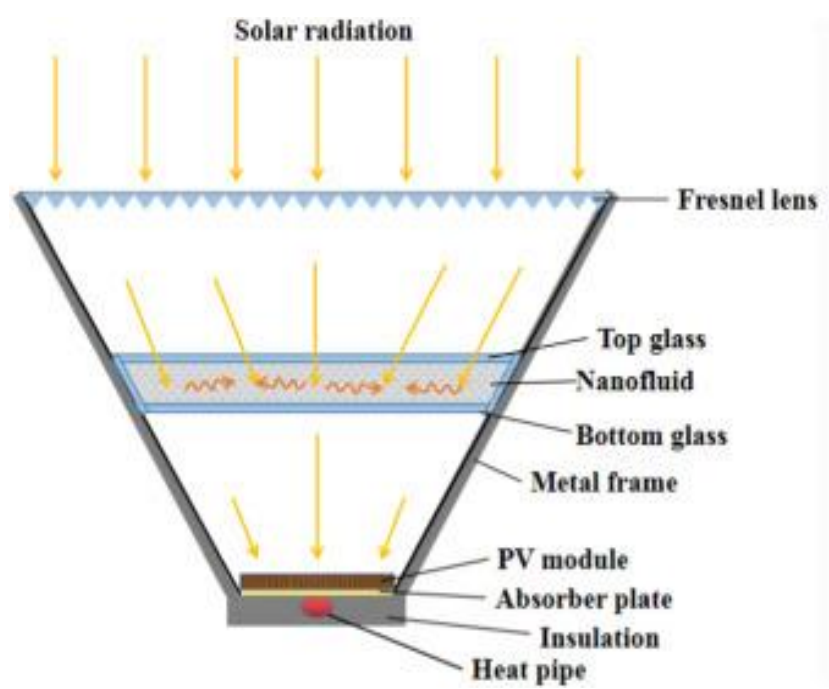

concentrating photovoltaic power to output. The photovoltaic modules achieved an average efficiency of $12.4 \%$.

Meanwhile, there is a decrease in thermal performance. Still, the overall design can provide a path to retrofit existing parabolic trough power plants to provide a $13 \%$ increase in power output using commercially available photovoltaic technology. Han et al. ${ }^{[88]}$ proposed a concentrating photovoltaic/thermal (CPV/T) system, shown in Fig. 16, which combines the advantages of $\mathrm{Ag} / \mathrm{CoSO}_{4}$-propylene glycol (PG) nanofluid based spectral beam splitter and heat pipe cooling technologies to enhance the solar energy conversion efficiency. Their results showed that when the concentration ratio varies from 1 to 8 suns, the average difference in the system average total efficiency of heat pipe cooling mode and no heat pipe mode is $10.4 \%$. Under the solar irradiance on a typical day with a concentration ratio of 5 suns, the system's instantaneous total efficiency reaches a maximum value of $73.20 \%$ at $17: 00$, with $7.55 \%$ coming from electricity. Its average total efficiency for the whole day is $53.66 \%$.

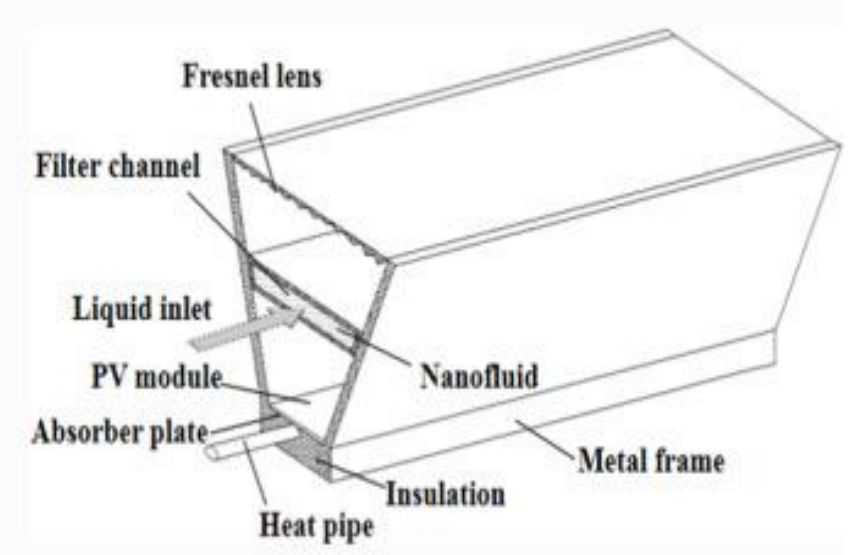

Fig. 16 Schematic of the nanofluid based spectral beam splitting CPV/T receiver with heat pipe cooling: (a) cross-section of the $\mathrm{CPV} / \mathrm{T}$ receiver and (b) 3D diagram of the CPV/T receiver, reproduced with the permission from [88], Copyright 2020 Elsevier. 


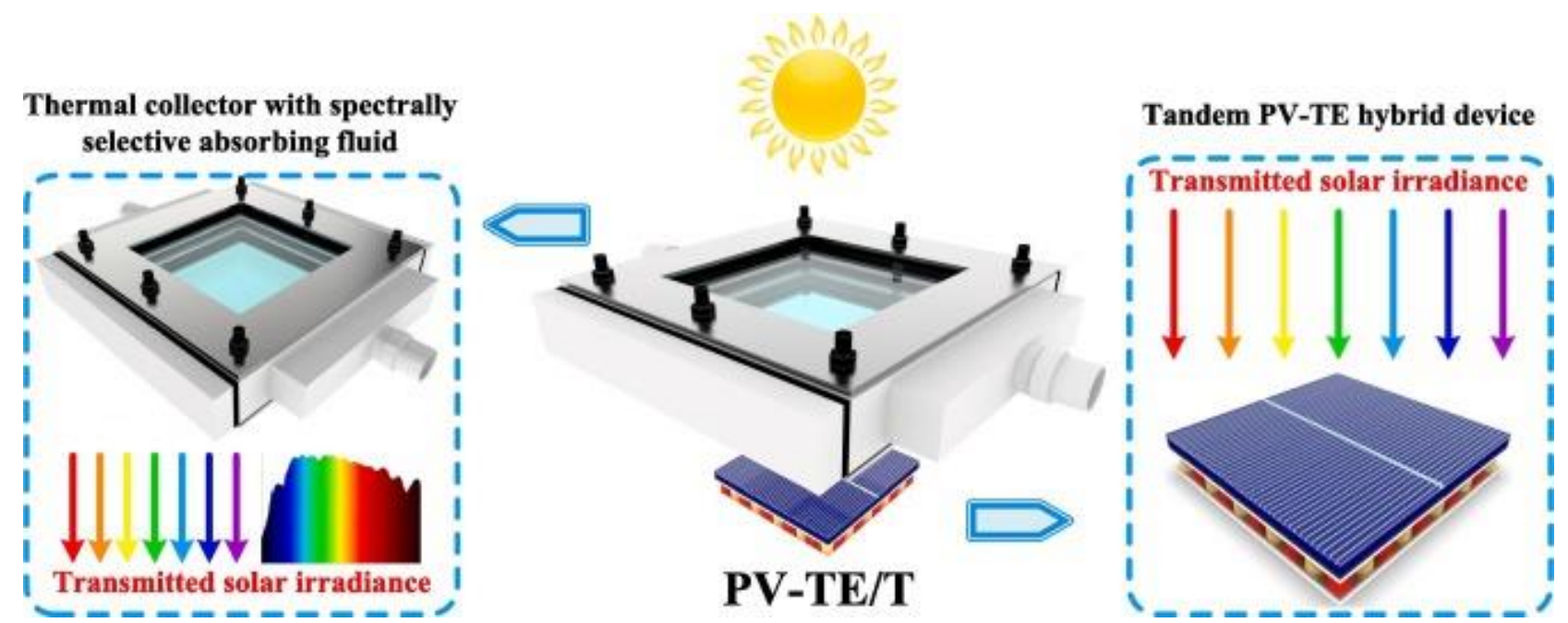

Fig. 17 Schematic of the photovoltaic-thermoelectric/thermal system, reproduced with the permission from [89], Copyright2019 Elsevier.

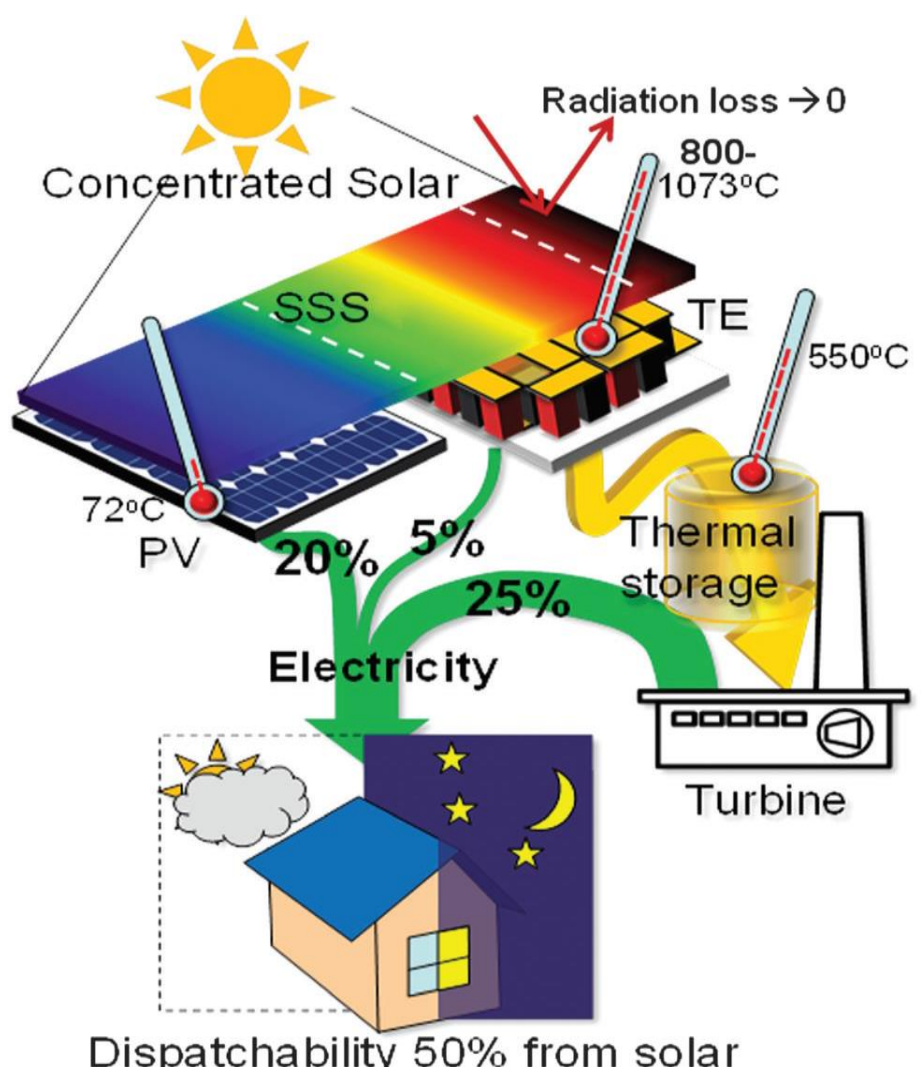

Fig. 18 The hybrid concept for generating electricity from solar power: concentrated sunlight is stored and converted via photovoltaics (PV), thermoelectrics (TE), and mechanical engines (ME) to achieve $50 \%$ conversion efficiency, reproduced with the permission from [91], Copyright 2016 Royal Society of Chemistry.

Recently, more diverse hybrid systems are proposed to couple multi-devices for efficient utilization of full-spectrum solar energy. Zhou et al. ${ }^{[89]}$ developed a photovoltaicsthermoelectric/thermal (PV-TE/T) system capable of full solar spectrum utilization. Fig. 17 shows the schematic of the PVTE/T system, which is composed of a tandem PV-TE component and a thermal collector with spectrally selective absorbing fluid. They proposed that the thermal collector in the PV-TE/T system cannot only make the output power more stable but enhance the efficiency. Yu et al. ${ }^{[00]}$ investigated a solar Micro-Channel Loop-Heat-Pipe Photovoltaic/ Thermal (MC-LHP-PV/T) system, which employs the co-axial tubular heat exchanger as the condenser, PV-bound multiple microchannel tubes array as the PV/evaporator, the upper-end liquid header with tiny holes as the liquid header and liquid/vapor separator, and the upper-end vapor header as the vapor collector and distributor. Under some specific operational conditions and the real weather solar radiation, the solar thermal efficiency of the system was in the range of $25.2 \%$ to $62.2 \%$, which are $17.20 \%$ and $33.31 \%$ higher than the overall solar efficiency of the existing PV/T and BIPV/T systems. Bermel et al. ${ }^{[91]}$ proposed a photovoltaic/thermoelectric/mechanical (PV/TE/ME) hybrid system. Fig. 18 shows the schematics of the PV/TE/ME system. In advance of other PV-TE system, the PV/TE/ME system is incorporated with a mechanical engine (e.g., a steam-driven Rankine cycle), which connects to thermal storage and the mechanical engine $550^{\circ} \mathrm{C}$. The thermal storage allows for significant dispatchability at a modest cost. As they proposed, the system can produce power for hours after sunset. Ideally, the system can achieve efficiencies over $50 \%$ using a combination of an InAlAs/InGaPt and em photovoltaics, ErAs:(InGaAs) ${ }_{1-x}(\text { InAlAs) })_{x}$ thermoelectrics, and mechanical Rankine cycles.

\section{Machine learning in solar energy utilization}

As mentioned in Arthur Samuel's work in 1959, ${ }^{[92]}$ machine learning (ML) refers to techniques, which can give computers the ability to learn automatically from experience (i.e., dataset) without being explicitly programmed by human beings. ML algorithms can be classified into three major algorithms: supervised learning, unsupervised learning, and reinforcement learning. Similar to the process of human learning 


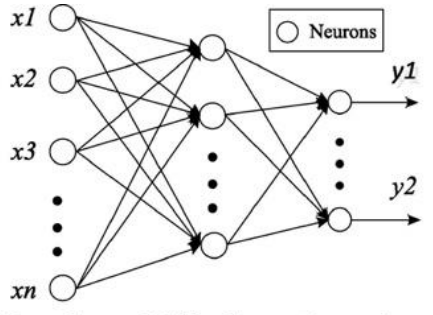

Input layer Hidden layer Output layer

(a) Artificial Neural Network

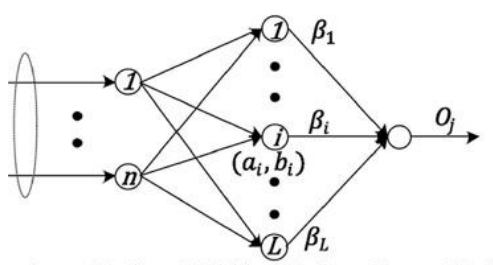

$n$ Input Nodes $L$ Hidden Nodes Output Node

(d) Extreme Learning Machine

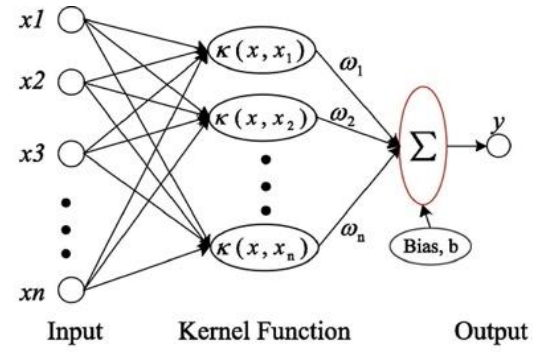

(b) SVM

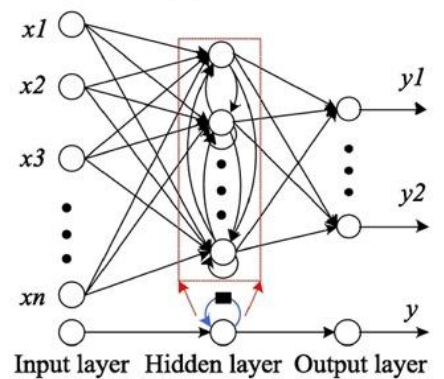

(e) Recursive Neuron Network

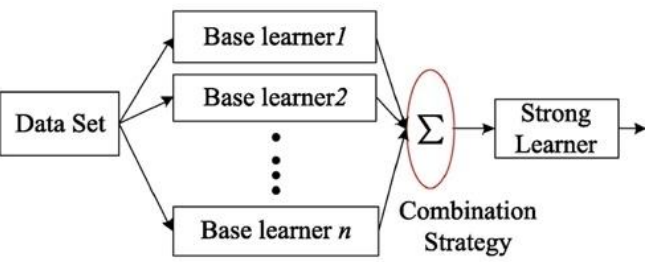

(c) Ensemble Learning

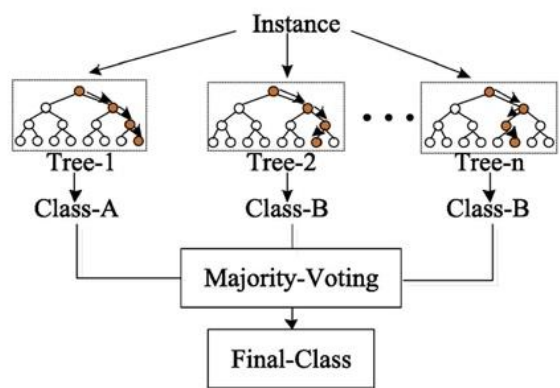

(f) Random Forest

Fig. 19 The typical structures of machine learning algorithms, reproduced with the permission from [97], Copyright 2020 Elsevier.

summarize the rules of past events and form the experience to deal with events in the future, machine learning is divided into three stages: input, learning, and output. The first stage is the collection and preprocessing of the sample data; the second is the training learning stage, which constantly updates the model through the training data until the expected optimization goal is achieved; the final output stage is to use the optimized model to make predictions or decisions on unknown data (or events).

Algorithms are the core of machine learning. The ML algorithms include artificial neural networks (ANN), support vector machine $\left(\mathrm{SVM},{ }^{[93]}\right.$ extreme learning machine (ELM), ${ }^{[94]}$ recurrent neural network (RNN), ${ }^{[95]}$ ensemble learning ${ }^{[96]}$ and random forest $(\mathrm{RF})$. The structures of typical ML algorithms are shown in Fig. 20(a-f).$^{\left[{ }^{[7]}\right.}$ It is necessary to have sufficient skill and patience to choose the proper model and adjust different hyperparameters to reach the optimal ML prediction.

So far, the ML method has been desirable in many fields, including designing materials ${ }^{[98]}$ and forecasting solar PV electricity generation. ${ }^{[99]}$ As discussed above, perovskites are one of the next-generation SC materials. Nevertheless, it is hard to find a novel, stable and environmental-friendly perovskite. Due to the massive database like Inorganic Crystal Structure Database (ICSD), ${ }^{[100]}$ and ML model based on the RF classification was successfully trained to predict the bandgap of inorganic perovskite materials, and 15,000 ABC2X structures of perovskite were used as training sets. ${ }^{[101]}$ Thirty previously unreported $\mathrm{Li}$ - and $\mathrm{Na}$-based perovskite with suitable bandgap (1.7-3.0 eV) were successfully found using this ML model. By using 212 sets of DFT calculation data as a training set, an ML model based on gradient boosting regression (GBR) algorithm was extended to predict the bandgaps of about 5000 hybrid organic-inorganic perovskites (HOIPs). ${ }^{[102]}$ Six lead-free HOIPs were expected with appropriate bandgaps, further verified by density functional theory (DFT) calculation. With the aid of ML methods, the amount of DFT calculations has been reduced.

For intelligent forecasting of the performances in PV/T collectors, Shamshirband et al. developed ELM models. ${ }^{[103]}$ The experimental procedure was induced to measure the temperatures, solar radiations, mass flow rate. ELM model can predict the $\mathrm{PV} / \mathrm{T}$ 's performance under the different personalized input variables. The PV/T performance can be optimized by the algorithm and procedure applied in solving the model. For one day ahead of power forecasting regarding a large-scale PV plant in China, Gao et al. ${ }^{[104]}$ classified the weather into ideal and non-ideal conditions and developed a discrete grey model for the power prediction. Based on different weather conditions, both PV forecasting models can be used by PV plant owners for hourly electric energy sale bids (based on forecasted PV hourly production) to day-ahead electric markets.

Photoelectrochemical (PEC) water splitting is the way to sustain carbon-free hydrogen production. ${ }^{[105]}$ Since Fujishima and Honda first demonstrated the PEC splitting of water in $1972,[106]$ hydrogen's PEC production has advanced significantly. The ultimate target for PEC hydrogen cost is $\$ 2.10 / \mathrm{kg},{ }^{[107]}$ which needs continuous efforts and technique improvements. In PEC hydrogen production, ML methods were used to predict new candidate materials for water splitting. For example, Greeley and Nørskov identified several surfaces and bulk alloys comparable to platinum from around 750 binary TM alloys. ${ }^{[108]}$ To understand the EC (Electrochemical) activity of materials for water splitting, Wexler et al. used a regularized-random-forest ML model to 


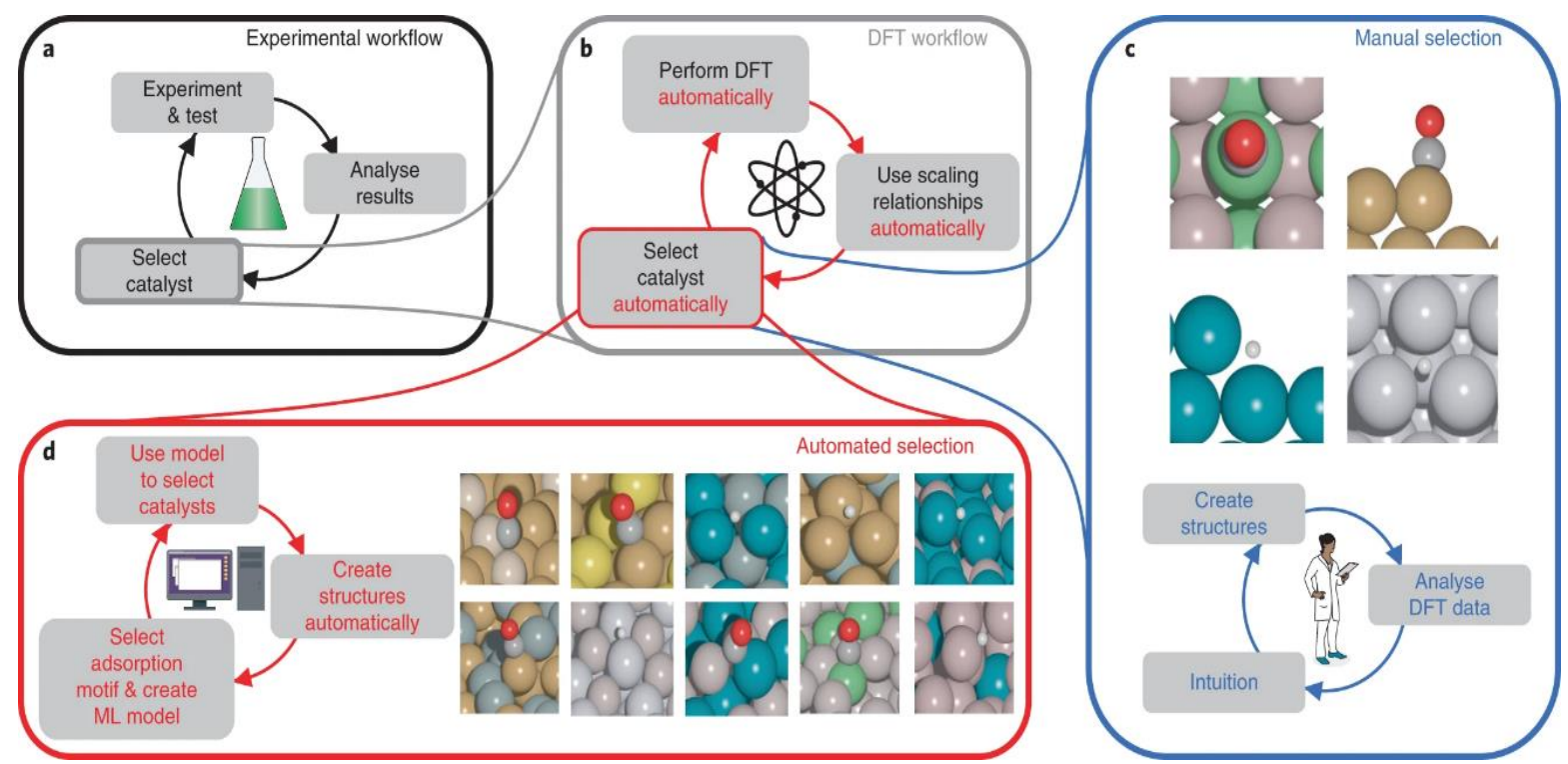

Fig. 20 A DFT workflow accelerates the experimental workflow for searching for catalysts (a) for screening the catalysts ab initio (b). (c), Traditional workflows (blue) require scientific intuition to select candidates for DFT screenings. (d), the workflow (red) uses machine learning $(\mathrm{ML})$ to select candidates systematically and automatically. The red text outlines the framework that this study used to perform active machine-learning and surrogate-based optimization, reproduced with the permission from [110], Copyright 2018 Kevin Tran et al.

describe the charge in determining the HER (hydrogen evolution reaction) activity of non-metal-doped $\mathrm{Ni}_{2} \mathrm{P}(0001){ }^{[109]}$ Tran and Ulissi created a framework (Fig. 8) that produces and stores DFT data continuously, which combines task and calculation management software with active machine-learning and surrogate-based optimization to enable the automated, systematic selection and execution of DFT calculations. ${ }^{[110]}$ They used this framework to identify 258 candidate surfaces from 102 intermetallics suitable for the HER. The studies indicate the promise of ML strategies in discovering new water-splitting photo-electrocatalysts.

Fig. 20. A DFT workflow accelerates the experimental workflow for searching for catalysts (a) for screening the catalysts ab initio (b). (c), Traditional workflows (blue) require scientific intuition to select candidates for DFT screenings. (d), the workflow (red) uses machine learning (ML) to select candidates systematically and automatically. The red text outlines the framework that this study used to perform active machine-learning and surrogate-based optimization. ${ }^{[110]}$

\section{Conclusions}

Solar energy is the most abundant alternative to fossil fuel. Photovoltaic technology is a direct and effective way to utilize solar energy. The mismatch between the absorption band of solar cells and the solar light band restricts solar energy's efficient use. In this paper, full-spectrum conversion and solar energy utilization with spectral modification and coupling solar thermal application are reviewed. Additionally, this paper also provides the recent progress of utilizing the ML method in solar energy utilization.

Spectral modification has been proposed as a way to achieve higher solar cell efficiencies. With the utilization of
UC materials for solar cells, a few studies have successfully harnessed greater energy from the solar spectrum. Although spectral modification has not broken the SQ limit, the continued research on both $\mathrm{UC}$ and $\mathrm{DC}$ to match the spectrum can excite prospects for expansion of solar PV.

Combining PV and thermal applications have been extensively studied. The technology has been proved to be effective in efficiency improvement. Still, it is challenging to balance the cooling performance and the utilization of the heat. There is an inevitable trade-off between improving the highgrade thermal energy utilization and lower PV efficiency. Therefore, the spectrum splitting method offers the potential for higher efficiencies, as each technology utilizes the solar spectrum over its optimal wavelength range. It is particularly recommended that higher-energy solar photons are being used with photovoltaics while the lower-energy solar photons are decoupled for thermal applications. With both theoretical and lab-scale experimental demonstrations, the hybrid systems are anticipated to have a promising efficiency.

With the development of computer science and the urgent need to design solar energy materials and forecast PV performances, ML methods in solar energy utilization can be introduced for remarkable achievements. There have been many successful examples to implement ML methods into solar energy utilization, in which circumstances, complicated computations, or predictions are necessary.

\section{Acknowledgment}

The authors are thankful for the financial support from the NSFC (No. 51888103/51606192) and the CAS Pioneer Hundred Talents Program. 


\section{Supporting information}

Not applicable.

\section{Conflict of interest}

There are no conflicts to declare.

\section{References}

[1] M S Dresselhaus, I L Thomas, Nature, 2001, 414, 332-7, doi: $10.1038 / 35104599$.

[2] N S Lewis, D G Nocera, P. Natl. A. Sci., 2006, 103, 15729, doi: 10.1073/pnas.0603395103.

[3] M. A. Green, Prog. Photovoltaics, 2001, 9, 123-35, doi: 10.1002/PIP.360.

[4] L Mazzarella, Y H Lin, S Kirner, A B Morales-Vilches, L Korte, S Albrecht, E. Crossland, B. Stannowski, C. Case, H. J. Snaith. R. Schlatman, Adv. Energy Mater., 2019, 9, 9, doi: 10.1002/aenm.201803241.

[5] D E Carlson, C R Wronski, Appl. Phys. Lett., 1976, 28, 671 3, doi: 10.1063/1.88617.

[6] S R Kurtz, A A Allerman, E D Jones, J M Gee, J J Banas, B E Hammons, Appl. Phys. Lett., 1999, 74, 729-31. doi: 10.1063/1.123105.

[7] H P Shen, T Duong, Peng J, D Jacobs, N D Wu, J B Gong, Y. Wu, S. K. Karuturi, X. Fu, K. Weber, X. Xiao, T P White and K Catchpolea Energy Environ. Sci. 2018, 11, 394-406, doi: 10.1039/C7EE02627G.

[8] K Yoshikawa, H Kawasaki, W Yoshida, T Irie, K Konishi, K Nakano, T Uto, D Adachi, M Kanematsu, H Uzu and K Yamamoto Nat. Energy, 2017, 2, 8, doi: 10.1038/nenergy.2017.32. [9] M J Kerr, A Cuevas, P Campbell, Prog. Photovoltaics., 2003, 11, 97-104, doi: 10.1002/pip.464.

[10] A Kojima, K Teshima, Y Shirai, T Miyasaka, J. Am. Chem. Soc. 2009, 131, 6050 doi: 10.1021/ja809598r.

[11] Statistical chart of maximum efficiency of laboratory solar cell by NREL.

[12] W Shockley, H J Queisser, J. Appl. Phys., 1961, 32, 510, doi: $10.1063 / 1.1736034$.

[13] X Y Huang, S Y. Han W Huang, X G Liu, Chem. Soc. Rev. 2013, 42, 173-201. doi: 10.1039/C2CS35288E.

[14] H Z Lian, Z Y Hou, M M Shang, D L Geng, Y Zhang, J Lin Energy. 2013, 57, 270-283, doi: 10.1016/j.energy.2013.05.019.

[15] B M van der Ende, L Aarts, A Meijerink, Phys. Chem. Chem. Phys., 2009, 11, 11081-11095, doi: 10.1039/B913877C.

[16] C Ortiz, R Chacartegui, J M Valverde, A Alovisio, J A Becerra, Energ. Convers. Manage., 2017, 149, 815-829, doi: 10.1016/j.enconman.2017.03.029.

[17] M Haase, H Schafer, Angew Chem. Int. Edit., 2011, 50, 580829, doi: 10.1002/anie.201005159.

[18] J C Goldschmidt, S. Fischer, Adv. Opt. Mater., 2015, 3, 51035, doi: 10.1002/adom.201500024.

[19] Dumont L, Cardin J, Benzo P, Carrada M, Labbe C, Richard AL, D C Ingram, W M Jadwisienczak, F Gourbilleau, Sol. Energy Mater. Sol. Cells, 2016, 145, 84-92, doi: 10.1016/j.solmat.2015.09.031.
[20] N Bloembergen, Phys. Rev. Lett., 1959, 2, 84-5. doi: 10.1103/PhysRevLett.2.84.

[21] A Nadort, J B Zhao, E M Goldys, Nanoscale, 2016, 8, 13099130, doi: 10.1039/C5NR08477F.

[22] W Park, D W Lu, S M Ahn, Chem. Soc. Rev., 2015, 44, 2940 62, doi: 10.1039/C5CS00050E.

[23] J Zhou, Q Liu, W Feng, Y Sun, F Y Li, Chem Rev., 201, 115, 395-465. doi: 10.1021/cr400478f.

[24] J F Suyver, A Aebischer, D Biner, P Gerner, J Grimm, S Heer, KW Krämer, C Reinhard, H.U.Güdel, Opt. Mater., 2005, 27, 1111-30, doi: 10.1016/j.optmat.2004.10.021.

[25] T N Singh-Rachford, F N Castellano, Coord. Chem. Rev., 2010, 254, 2560-73, doi: 10.1016/j.ccr.2010.01.003.

[26] T Trupke, M A Green, P Wurfe, J. Appl. Phys., 2002, 92, 4117-22, doi: 10.1063/1.1505677.

[27] J Wu, J Wang, J Lin, Z Lan, Q Tang, M Huang, Y. Huang L. Fan, Q. Li, Z Tang, Adv. Energy Mater., 2012, 2, 78-81, doi: 10.1002/aenm.201100531.

[28] M He, X C Pang, X Q Liu, B B Jiang, Y J He, H Snaith, Z Lin, Angew Chem. Int. Edit., 2016, 55, 4280-4, doi: 10.1002/anie.201600702.

[29] Martin-Ramos P, Silva MR, Coya C, Zaldo C, Alvarez AL, Alvarez-Garcia S, A Bejab and J Martín-Gile, J. Mater. Chem. C, 2013, 1, 2725-34, doi: 10.1039/c3tc00649b.

[30] A Shalav, B S Richards, T Trupke, K W Kramer, H U Gudel, Appl. Phys. Lett., 2005, 86, 3, doi: 10.1063/1.1844592.

[31] P Ramasamy, J Kim, Chem. Commun., 2014, 50, 879-81, doi: 10.1039/C3CC47290F.

[32] B S Richards, Sol. Energy Mater. Sol. Cells. 2006, 90, 232937, doi: 10.1016/j.solmat.2006.03.035.

[33] L Zhou, Y L Tan, D X Ji, B Zhu, P Zhang, J Xu, Sci. Adv., 2016, 2, 8, doi: 10.1126/sciadv.1501227.

[34] B L Reid, S Stagni, J M Malicka, M Cocchi, G S Hanan, M I Ogden, and M. Massi, Chem. Commun., 2014, 50, 11580-2. doi: 10.1039/C4CC04961F.

[35] J H Cheon, D Y Jung, S K Choi, K S Ahn, DK Lee, J H Kim, Met. Mater. Int., 2013, 19, 1365-8, doi: 10.1007/s12540-0130642-0.

[36] S N Qu, X Y Wang, Q P Lu, X Y Liu, L J Wang Angew Chem. Int. Edit., 2012, 51, 12215-8, doi: 10.1002/anie.201206791.

[37] S Fischer, H,Steinkemper P Loper, M Hermle, J C Goldschmidt, J. Appl. Phys., 2012, 111, 13. doi: 10.1063/1.3674319.

[38] X L Wang, Z L Zhang, J Q Qin, W J Shi, Y F Liu, H P Gao, Y Mao, Electrochim. Acta, 2017, 245, 839-45, doi: 10.1016/j.electacta.2017.06.032.

[39] X S Lai, X T Li, X D Lv, Y Z Zheng, F L Meng, X Tao, J. Power Sources, 2017, 372, 125-33, doi: 10.1016/j.jpowsour.2017.10.067.

[40] S Ivanova, F Pelle, J. Opt. Soc. Am. B-Opt. Phys., 2009, 26, 1930-8, doi:10.1364/JOSAB.26.001930.

[41] F Lahoz, Optics. Letts., 2008, 33, 2982-4, doi: 10.1364/OL.33.002982. 
[42] Q Li, J Lin, J Wu, Z Lan, Y Wang, F Peng, M Huang, Electrochim. Acta, 2011, 56, 4980-4, doi: 10.1016/j.electacta.2011.03.125.

[43] Z Q Li, X D Li, Q Q Liu, X H Chen, Z Sun, C Liu, X J Ye and S M Huang, Nanotechnology, 2012, 23, 8, doi: 10.1088/0957-4484/23/2/025402.

[44] H Y Lin, H N Chen, T H Wu, C S Wu, Y K Su, S Y Chu, $J$. Amercn. Ceramic Soc., 2012, 95, 3172-9. doi: 10.1111/j.15512916.2012.05281.x.

[45] G B Shan, G P Demopoulos, Adv Mater., 2010, 22, 4373, doi: 10.1002/adma.201001816.

[46] H Q Wang, M Batentschuk, A Osvet, L Pinna, C J Brabec, Adv. Mater., 2011, 23, 2675-80, doi: 10.1002/adma.201100511.

[47] F Yazdanifard, M Ameri, Renew. Sustain. Energy Revs., 2018, 97, 529-553. doi: 10.1016/j.rser.2018.08.053.

[48] R Kumar, M A Rosen, Appl. Energ., 2011, 88, 3603-14, doi: 10.1016/j.apenergy.2011.04.044.

[49] P Ooshaksaraei, K Sopian, S H Zaidi, R Zulkifli, Renew. Energ., 2017, 102, 279-93. doi: 10.1016/j.renene.2016.10.043.

[50] S R Abdallah, H Saidani-Scott, O E Abdellatif, Sol. Energy, 2019, 181, 108-15. doi: 10.1016/j.solener.2019.01.088.

[51] A H A Al-Waeli, M T Chaichan, H A Kazem, K Sopian, A Ibrahim, S Mat, M H Ruslan, Energy, 2018, 151, 33-44, doi: 10.1016/j.energy.2018.03.040.

[52] X Han, X Chen, Q Wang, S M Alelyani, J Qu, Sol. Energy, 2019, 177, 387-94, doi: 10.1016/j.solener.2018.11.037.

[53] W An, L Chen, T Liu, Y Qin, Sol. Energy, 2018, 176, 14656, doi: 10.1016/j.solener.2018.10.029.

[54] S Hassani, R Saidur, S Mekhilef, R A Taylor, Energ. Convers. Manage., 2016, 123, 431-444, doi: 10.1016/j.enconman.2016.06.061.

[55] C Zhang, C Shen, Q Yang, S Wei, C Sun, Sol. Energy, 2020, 208, 623-36, doi: 10.1016/j.solener.2020.08.037.

[56] H N Chaudhry, B R Hughes, S A Ghani, Renew. Sustain. Energy Revs., 2012, 16, 2249-59, doi: 10.1016/j.rser.2012.01.038. [57] M Moradgholi, S Mostafa Nowee, A Farzaneh, Sol. Energy, 2018, 164, 243-250. doi: 10.1016/j.solener.2018.02.055.

[58] H Jouhara, M Szulgowska-Zgrzywa, M A Sayegh, J Milko, J Danielewicz, T K Nannou, S P Lester, Energy, 2017, 136, 11725, doi: 10.1016/j.energy.2016.04.070.

[59] H Jouhara, J Milko, J Danielewicz, M A Sayegh, M Szulgowska-Zgrzywa, J B Ramos, Energy, 2016, 108, 148-54, doi: 10.1016/j.energy.2015.07.063.

[60] H Chen, L Zhang, P Jie, Y Xiong, P Xu, H Zhai, Appl. Energ., 2017, 190, 960-80, doi: 10.1016/j.apenergy.2016.12.145.

[61] X Yang, L Sun, Y Yuan, X Zhao, X Cao, Renew. Energy, 2018, 119, 152-9, doi: 10.1016/j.renene.2017.11.094.

[62] S Mousavi, A Kasaeian, M B Shafii, M H Jahangir, Energ. Convers. Manage., 2018, 163, 187-95. doi: 10.1016/j.enconman.2018.02.039.

[63] A Kazemian, M Hosseinzadeh, M Sardarabadi, M Passandideh-Fard, Energy, 2018, 162, 210-23, doi: 10.1016/j.energy.2018.07.069.

[64] Y Yu, H Yang, J Peng, E Long, Energy, 2019, 175, 300-308, doi: 10.1016/j.energy.2019.03.054.
[65] M S Hossain, A K Pandey, J Selvaraj, N A Rahim, M M Islam, V V Tyagi, Renew. Energy, 2019, 136, 1320-36, doi: 10.1016/j.renene.2018.10.097.

[66] N S Nazri, A Fudholi, W Mustafa, C H Yen, M Mohammad, M H Ruslan, M Sopian, Renew. Sustain. Energy Revs., 2019, 111, 132-44, doi: 10.1016/j.rser.2019.03.024.

[67] A Rezania, L A Rosendahl, Appl. Energ., 2017, 187, 380-9, doi: 10.1016/j.apenergy.2016.11.064.

[68] Y Vorobiev, J González-Hernández, P Vorobiev, L Bulat, Sol. Energy, 2006, 80, 170-6, doi: 10.1016/j.solener.2005.04.022.

[69] E Yin, Q Li, Sol. Energy, 2020, 211, 147-57, doi: 10.1016/j.solener.2020.09.049.

[70] T H Kil, S Kim, D H Jeong, D M Geum, S Lee, S J Jung, S Kim, C Park, J S Kim, J M Baik, K S Lee, C Z Kim W J Choi, S H Baek Nano Energy, 2017, 37, 242-7, doi: 10.1016/j.nanoen.2017.05.023.

[71] A Tiwari, O A Alashqar, N Dimri, Energ. Convers. Manage., 2020, 205, 112378, doi: 10.1016/j.enconman.2019.112378.

[72] G Li, S Shittu, X Ma, X Zhao, Energy, 2019, 171, 599-610, doi: 10.1016/j.energy.2019.01.057.

[73] J Zhang, Y Xuan, Sol. Energy, 2019, 177, 293-8, doi: 10.1016/J.SOLENER.2018.11.012.

[74] J Zhang, H Zhai, Z Wu, Y Wang, H Xie, Sol. Energ. Mat. Sol. $C, 2020,215,110666$. doi: 10.1016/j.solmat.2020.110666.

[75] H Wang, W Li, T Liu, X Liu, X Hu, Energ. Convers. Manage., 2019, $\quad \mathbf{1 8 3}, \quad 97-108, \quad$ doi: 10.1016/j.enconman.2018.12.106.

[76] B Agrawal, G N Tiwari, Energ. Buildings, 2010, 42, 14721481, doi: 10.1016/j.enbuild.2010.03.017.

[77] M Farshchimonfared, J I Bilbao, A B Sproul, Sol. Energy, 2016, 136, 15-22. doi: 10.1016/j.solener.2016.06.048.

[78] J Guo, J I Bilbao, A B Sproul, Renew. Energy, 2020, 162, 1273-84, doi: 10.1016/j.renene.2020.08.050.

[79] S Muhammad-Bashir, M Al-Oufi, M Al-Hakami, MA Nadeem, K Mudiyanselage, H Idriss. Sol. Energy, 2020, 205, 461-464. doi: 10.1016/j.solener.2020.05.077.

[80] M Yamaguchi, T Takamoto, K Araki, N Ekins-Daukes, Sol. Energy, 2005, 79, 78-85, doi: 10.1016/j.solener.2004.09.018.

[81] M Wang, Z Wang, X Gong, Z Guo, Renew. Sustain. Energy Revs., 2014, 29, 573-588, doi: 10.1016/j.rser.2013.08.090.

[82] E Skoplaki, J A Palyvos, Sol. Energy, 2009, 83, 614-624, doi: 10.1016/j.solener.2008.10.008.

[83] X Vitart, A Le Duigou, P Carles, Energ. Convers. Manage., 2006, 47, 2740-2747, doi: 10.1016/j.enconman.2006.02.010.

[84] P Charvin, S Abanades, F Lemort, G Flamant, Energ. Fuel, 2007, 21, 2919-2928. doi: 10.1021/ef0701485.

[85] C H Henry, J. Appl. Phys., 1980, 51, 4494-500, doi: $10.1063 / 1.328272$.

[86] F Crisostomo, N Hjerrild, S Mesgari, Q Li, R A Taylor, Appl. Energ., 2017, 193, 1-14. doi: 10.1016/j.apenergy.2017.02.028.

[87] R Wingert, H O'Hern, M Orosz, P Harikumar, K Roberts, T Otanicar, Sol. Energy, 2020, 202, 1-9, doi: 10.1016/j.solener.2020.03.066.

[88] X Han, X Zhao, X Chen, Renew. Energy, 2020, 162, 55-70. doi: 10.1016/j.renene.2020.07.131. 
[89] Y P Zhou, Li M-J, Hu Y-H, Ma T. Design and experimental investigation of a novel full solar spectrum utilization system. Appl. Energ., 2020, 260, 114258. doi: 10.1016/j.apenergy.2019.114258.

[90] M Yu, F Chen, S Zheng, J Zhou, X Zhao, Z Wang, G Li, J Li, Yi Fan, J Ji, T M O Diallo, D. Hardy, Appl. Energ, 2019, 256, 113929, doi: 10.1016/j.apenergy.2019.113929.

[91] P Bermel, K Yazawa, J L Gray, X Xu, A Shakouri, Energy Environm. Sci., 2016, 9, 2776-88. doi: 10.1039/C6EE01386D.

[92] A L Samuel, IBM J. Res. Dev., 1959, 3, 211, doi: 10.1147/rd.33.0210.

[93] J L Fan, X K Wang, L F Wu, H M Zhou, F C Zhang, X Yu, X Lu, Y Xiang, Energy Conv. Manag., 2018, 164, 102-11, doi: 10.1016/j.enconman.2018.02.087.

[94] I Majumder, P K Dash, R Bisoi, Energy Conv. Manag., 2018, 171, 787-806, doi: 10.1016/j.enconman.2018.06.021.

[95] H Su, E Zio, J J Zhang, M J Xu, X Y Li, Z J Zhang, Energy, 2019, 178, 585-97, doi: 10.1016/j.energy.2019.04.167.

[96] A Fouilloy, C Voyant, G Notton, F Motte, C Paoli, M L Nivet E. Guillot, J. L. Duchauda, Energy, 2018, 165, 620-629, doi: 10.1016/j.energy.2018.09.116.

[97] H Z Wang, Y Y Liu, B Zhou, C B Li, G Z Cao, N Voropai, E Barakhtenko, Energy Conv. Manag., 2020, 214, 17, doi: 10.1016/j.enconman.2020.112909.

[98] HS Wang, Y J Ji, Y Y Li, Wiley Interdiscip Rev-Comput. Mol. Sci., 2020, 10, 18, doi: 10.1002/wcms.1421.

[99] T Ahmad, H X Chen, Sust. Cities. Soc., 2020, 54, 27, doi: 10.1016/j.scs.2019.102010.

[100] A Belsky, M Hellenbrandt, V L Karen, P Luksch, Acta Crystallogr. Sect. B-Struct. Sci., 2002, 58, 364-9. doi: 10.1107/s0108768102006948.

[101] K Takahashi, L Takahashi, I Miyazato, Y Tanaka, ACS Photonics, 2018, 5, 771-5, doi: 10.1021/acsphotonics.7b01479.

[102] S H Lu, Q H Zhou, YX Ouyang, Y L Guo, Q Li, J L Wang, Nat. Commun., 2018, 9, 8, doi: 10.1038/s41467-018-05761-w.

[103] J C Mojumder, H C Ong, W T Chong, N Izadyar, S Shamshirband, Renew. Sust. Energ. Rev., 2017, 72, 1366-1378, doi: 10.1016/j.rser.2016.11.225.

[104] M M Gao, J J Li, F Hong, D T Long, Energy, 2019, 187, 12, doi: 10.1016/j.energy.2019.07.168.

[105] K Maeda, ACS Catal., 2013, 3, 1486-503. doi: 10.1021/cs4002089.

[106] A Fujishima, K Honda, Nature, 1972, 238, 37, doi: 10.1038/238037a0.

[107] N Gokon, Y Osawa, D Nakazawa, T Kodma, Int. J. Hydrogen Energ., 2009, 34, 1787-800, doi: 10.1016/j.ijhydene.2008.12.018.

[108] J Greeley, J K Norskov, Surf. Sci., 2007, 601, 1590-8, doi: 10.1016/j.susc.2007.01.037.

[109] R B Wexler, J M P Martirez, A M Rappe, J. Am. Chem. Soc., 2018, 140, 4678-83, doi: 10.1021/jacs.8b00947.

[110] K Tran, Z W Ulissi, Nat. Catal., 2018, 1, 696-703. doi: 10.1038/s41929-018-0142-1.

\section{Author information}

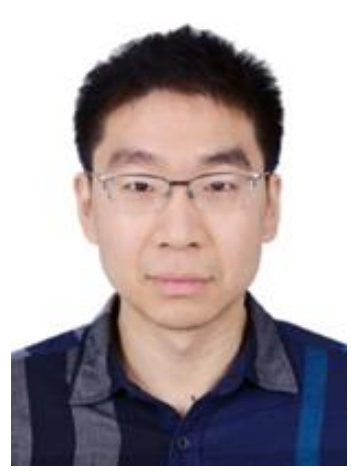

Chen Chen is a postdoctoral researcher at the Institute of Engineering Thermophysics, Chinese Academy of Sciences. His research focuses on solar thermochemical production of $\mathrm{H} 2$, concentrated solar power applications and Solar thermochemical energy storage. He received a master's degree in Mechanical Engineering from Columbia University in 2013 and $a$ PhD degree in Mechanical Engineering from UCLA.

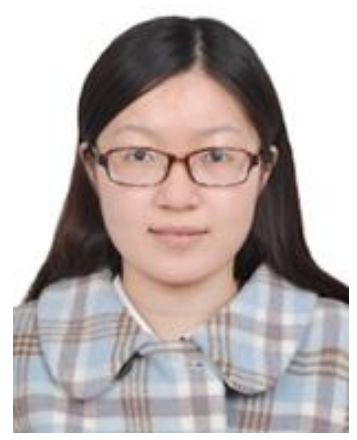

Xixi Xie is a post-doctoral researcher at the Institute of Engineering Thermophysics, Chinese Academy of Sciences. Her research focuses on preparation and simulation calculation of solar cells, especially for the semitransparent and tandem perovskite solar cells. She received both the master's and the PhD degree in Physics from Peking University.

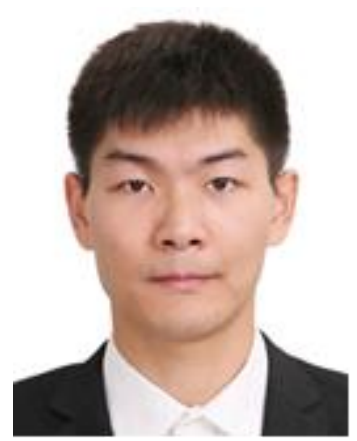

Ming Yang is an associate professor at the Institute of Engineering Thermophysics, Chinese Academy of Sciences, China. His research focuses on micro-scale heat transfer, concentrated solar power applications and topological materials. He graduated from Institute of Physics, Chinese Academy of Sciences and obtained PhD degree in theoretical physics in 2015. In 2018-2019, he was a visiting scholar in University of Colorado at Boulder.

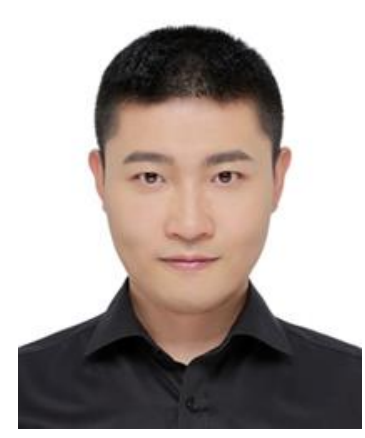

Hang Zhang is a professor in Institute of Engineering Thermophysics, Chinese Academy of Sciences and University of Chinese Academy of Sciences, in China. His research focuses on mechanisms and advanced technology on energy transport and conversions in emerging materials and equipment. He received his $\mathrm{PhD}$ degree in Physics from University of California, Riverside and then joined Caltech as a postdoctoral scholar. 


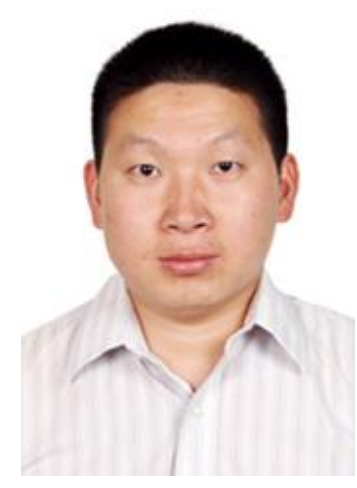

Qibin Liu is a professor at the Institute of Engineering Thermophysics, Chinese Academy of Sciences and University of Chinese Academy of Sciences, China. His research focuses on solar thermochemical production of $\mathrm{H}_{2}$, concentrated solar power applications and Solar-clean fuel distributed energy system. He holds a diploma and a M.Sc. both in power engineering and engineering thermal engineering and engineering thermal physics from the Institute of

Engineering Thermophysics, Chinese Academy of Sciences.

Publisher's Note: Engineered Science Publisher remains neutral with regard to jurisdictional claims in published maps and institutional affiliations. 